\title{
EVALUATION OF RIGHT ILIAC FOSSA MASS-A RETROSPECTIVE STUDY
}

\author{
G. Raja Billy Graham ${ }^{1}$, V. Vijayabhasker ${ }^{2}$ \\ 1 Professor, Department of General Surgery, Government Chengalpattu Medical College. \\ ${ }^{2}$ Assistant Professor, Department of General Surgery, Melmaruvathur Adhiparasakthi Institute of Medical Sciences and Research, \\ Melmaruvathur.
}

\begin{abstract}
Mass in right iliac fossa is one of the common clinical surgical entity with varied etiologies, involving intra peritoneal organs like vermiform appendix, caucus, ileum, retroperitoneal structures like kidneys, blood vessels etc., and abdominal wall masses like desmoids tumor. To know the etiology and the various pattern of presentation of right iliac fossa mass in our institution a retrospective study was designed including all adult patients diagnosed to have a mass in right iliac fossa. Pediatric patients and female patients having a mass due to gynaecological diseases were excluded from this study. All clinical parameters, radiological investigations, biochemical investigations, endoscopy, cytology, biopsy were collected and analysed systematically.
\end{abstract}

\section{KEYWORDS}

Carcinoma Caecum, Appendicular Mass, Rif Mass, Psoas Abscess, Ileocaecal Tuberculosis, Crohn’s Disease.

HOW TO CITE THIS ARTICLE: Graham GRB, Vijayabhasker V. Evaluation of right iliac fossa mass-a retrospective study. J Evolution Med Dent Sci 2016;5(3):200-214, DOI: 10.14260/jemds/2016/45

\section{INTRODUCTION}

Right iliac fossa mass may arise from parietal wall or intraperitoneum or retroperitoneum. Mass may arise from right iliac regional structures or extended from adjacent structures.

\section{Various Causes for Right Iliac Fossa Mass Parietal Wall Masses}

Lipoma, desmoid tumor, pyogenic abscess and haematoma, iliac or appendicular abscess burrowing into abdominal wall.

\section{Intraperitoneal Masses}

Appendicular abscess or mass, ileocaecal tuberculosis, carcinoma caecum, mesenteric adenitis, iliac nodes, typhlitis, Crohn's disease, actinomycosis, distended gallblader, ovarian cysts, fibroid uterus, tubo-ovarian mass, occasionally intussusception, amoeboma, diverticular disease.

\section{Retroperitoneal Masses}

Sarcoma, aneurysm, psoas abscess, undescended testis, unascended kidney and tumour from ilium and cartilage.

Appendicular pathology is commonest cause for right iliac fossa mass (Either appendicular mass or abscess). Other common causes are ileo-caecal tuberculosis and carcinoma caecum.

Appendicular mass is formed by inflamed appendix adherent with dilated ileum, greater omentum and caecum. ${ }^{1}$ Appendicular abscess due to suppuration in an acute appendicitis or suppuration in an already formed appendicular mass. ${ }^{1}$ Abdominal tuberculosis is common in developing countries like India. It is sixth most common type

Financial or Other, Competing Interest: None.

Submission 10-11-2015, Peer Review 11-11-2015,

Acceptance 19-11-2015, Published 09-01-2016.

Corresponding Author:

Dr. G. Raja Billy Graham,

No. 53, Vedhachalam Nagar,

Chengalpattu,

Kanchipuram-603001,

Tamilnadu.

E-mail: grbgraham@gmail.com

DOI:10.14260/jemds/2015/45 of extrapulmonary tuberculosis. Its incidence is high in HIV infected patients. (2) Ileo-caecal tuberculosis is commonest type of abdominal tuberculosis due to presence of Peyer's patches and stasis of luminal contents favoured by ileo-caecal valve.

Commonest type of carcinoma in caecum is adenocarcinoma. Third common site in large bowel carcinoma (12\%). Diet with lack of fibres and high fat increases risk. Dietary vitamins A, C, E (Antioxidants) and Zinc and high fibre diet reduces the risk. Diagnosis of right iliac fossa mass mainly depends on complete clinical examination, radiological, biochemical, microbiological and pathological investigations. Commonest cause of right iliac fossa mass in our country is appendicular mass or abscess, ileo-caecal tuberculosis and carcinoma caecum.

\section{OBJECTIVES OF THE STUDY}

To study the aetiology, pattern of presentation, management and complications in patients with right iliac fossa mass in our institution.

\section{MATERIALS AND METHODS}

This retrospective study was carried out in our institution over a period of two years from October 2010 to October 2012. All patients who are provisionally diagnosed to have mass in the right iliac fossa by clinical evaluation are included in the study. All datas including age, gender, relevant history, investigations (Complete blood count, Blood grouping and Rh typing, HIV I and II, Chest radiograph, Ultrasound abdomen and pelvis, CT Scan abdomen and pelvis, IVP and barium follow through and enema, FNAC, Biopsy) were done to conclude the final diagnosis and appropriate treatment and postoperative complications and final histopathological reports were recorded in the standard forms. Cases are selected by following Inclusion and exclusion criteria;

\section{Inclusion Criteria}

All the cases admitted with Right iliac fossa mass in our institution.

\section{Exclusion Criteria}

Female patients with gynaecological diseases. Paediatric age group ( $<12$ years) patients with right iliac fossa mass. 


\section{OBSERVATION AND RESULTS}

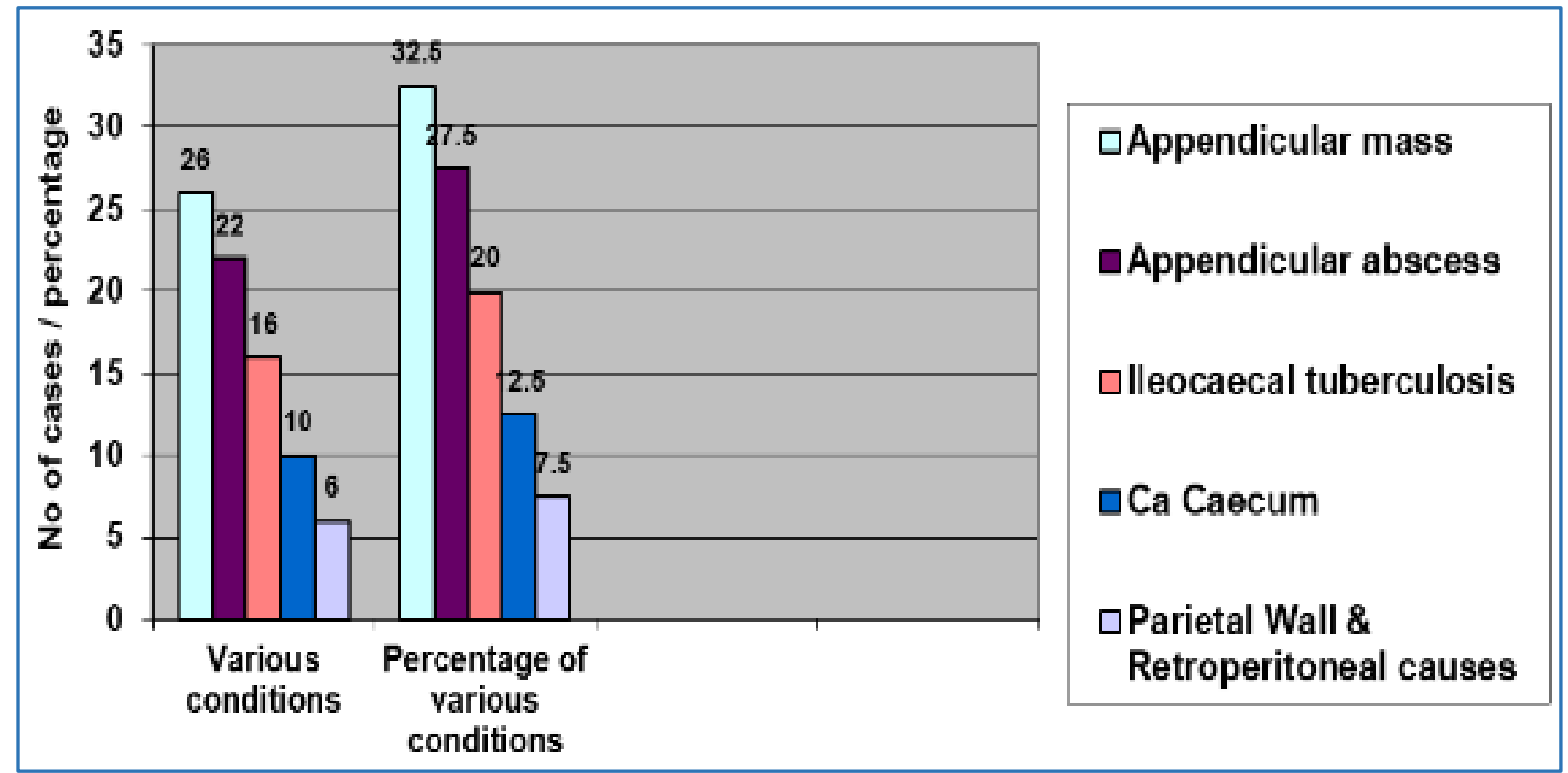

Fig. 1: Incidence of various conditions

In our study of 80 cases, $60 \%$ percent of cases are related to appendicular pathology; $20 \%$ of cases are related to ileo-caecal tuberculosis, $12.5 \%$ cases are related to carcinoma caecum, $7.5 \%$ of cases are related to various type of parietal wall and retroperitoneal causes like Psoas abscess, Retroperitoneal Schwannoma, Desmoid tumour, Rectus sheath haematoma. One case of carcinoma caecum was associated with ileo-caecal tuberculosis.

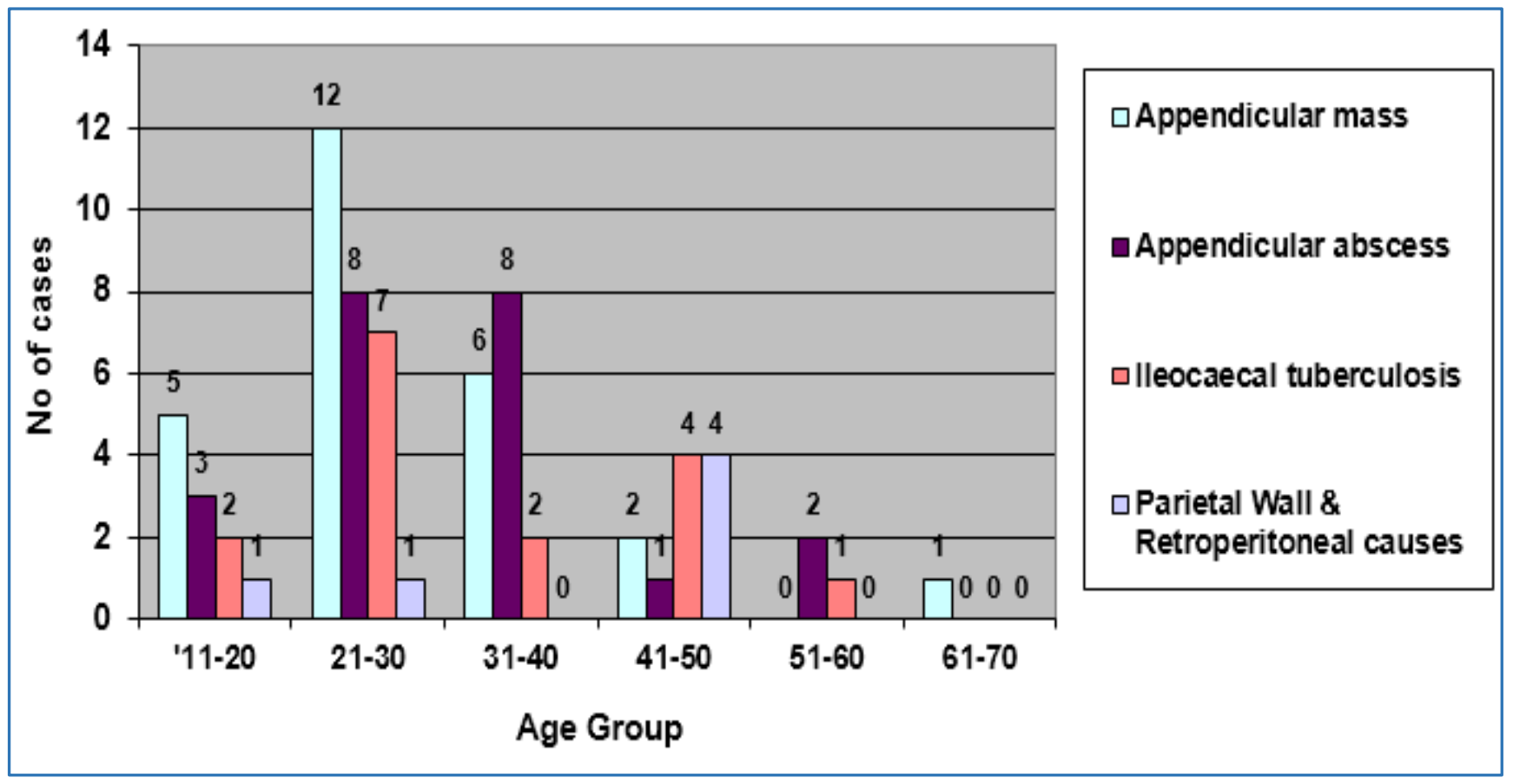

Fig. 2: Age Incidence

In our study of 80 cases, youngest patient was of age 13 year male, oldest patient was of age 70 year male, common age group was $20-50$ years $(72.5 \%)$. Appendicular pathology commonly presented in the $3^{\text {rd }}$ decade followed by $4^{\text {th }}$ and $2^{\text {nd }}$ decade. Ileo-caecal tuberculosis is common in 20-50 years of age group, carcinoma caecum is common in $6^{\text {th }}$ decade. 


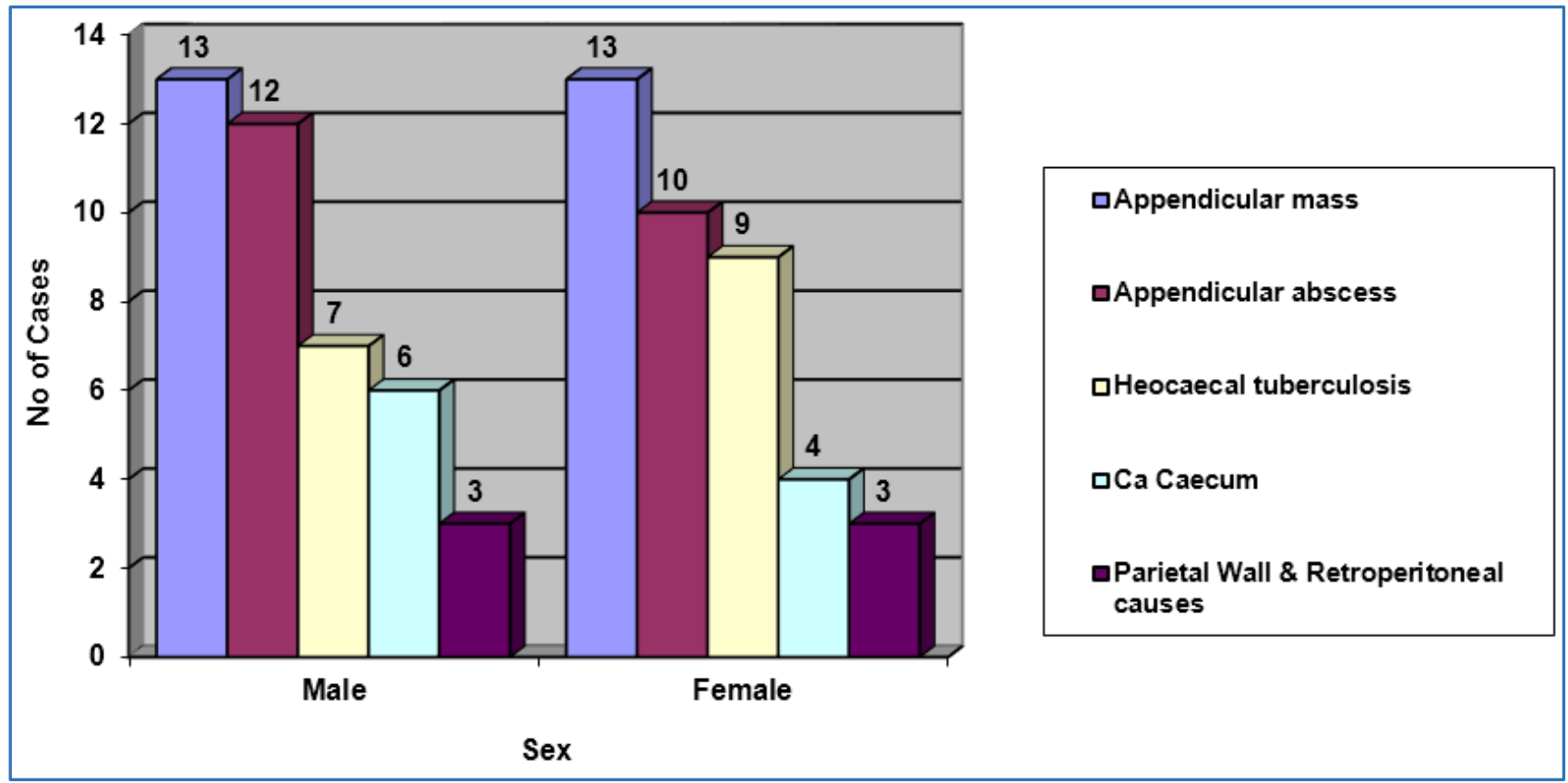

Fig. 3: Sex Incidence

In our study of 80 cases, appendicular pathology either appendicular mass or abscess has incidence of $52 \%$ in males and $48 \%$ in females. In ileo-caecal tuberculosis incidence in males is $44 \%$ and in females is $56 \%$. Carcinoma caecum is common in males (60\%) than in females (40\%). Overall, incidence in males is $51 \%$ and in females is $49 \%$.

\section{SOCIOECONOMICAL STATUS}

In our study $60 \%$ of cases have low socio-economic status. Majority of ileo-caecal tuberculosis cases are from low socio-economic status.

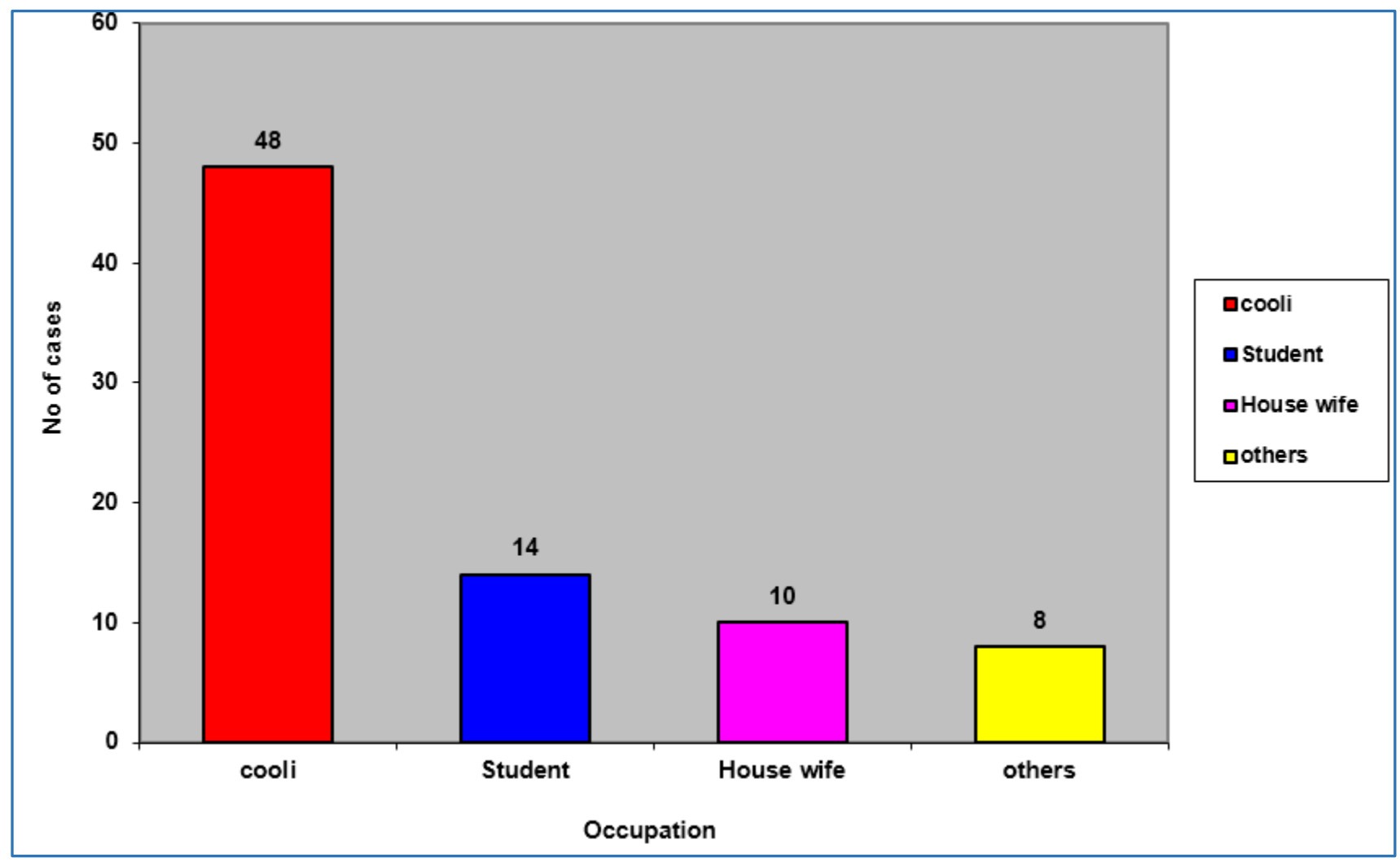

Fig. 4: Socioeconomic Status 


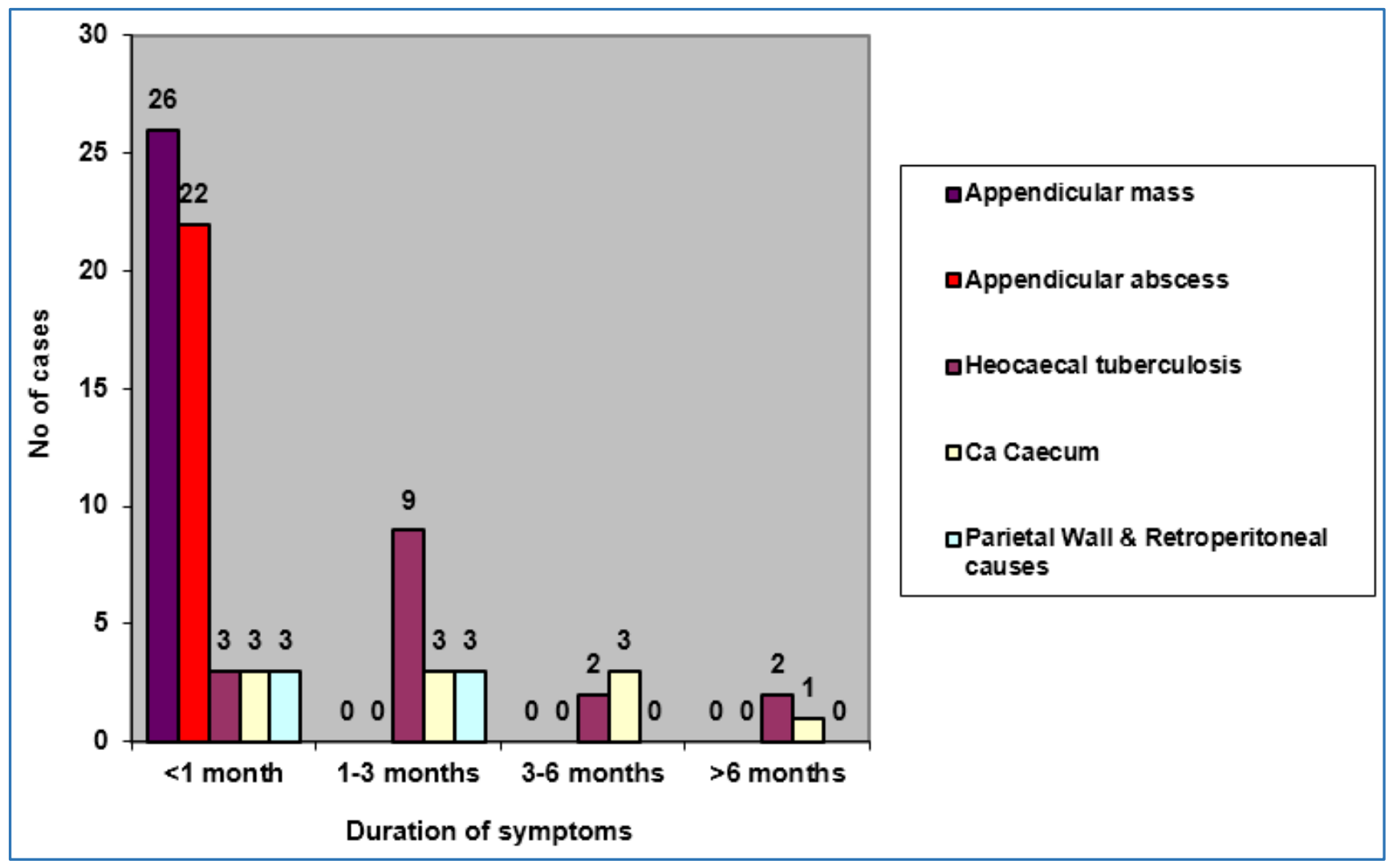

Fig. 5: Duration of Symptoms

Duration of illness in appendicular pathology is less than one month. In majority of ileo-caecal tuberculosis, patients had symptoms for 1-3 months. In majority of carcinoma caecum, patients had symptoms for 1-6 months.

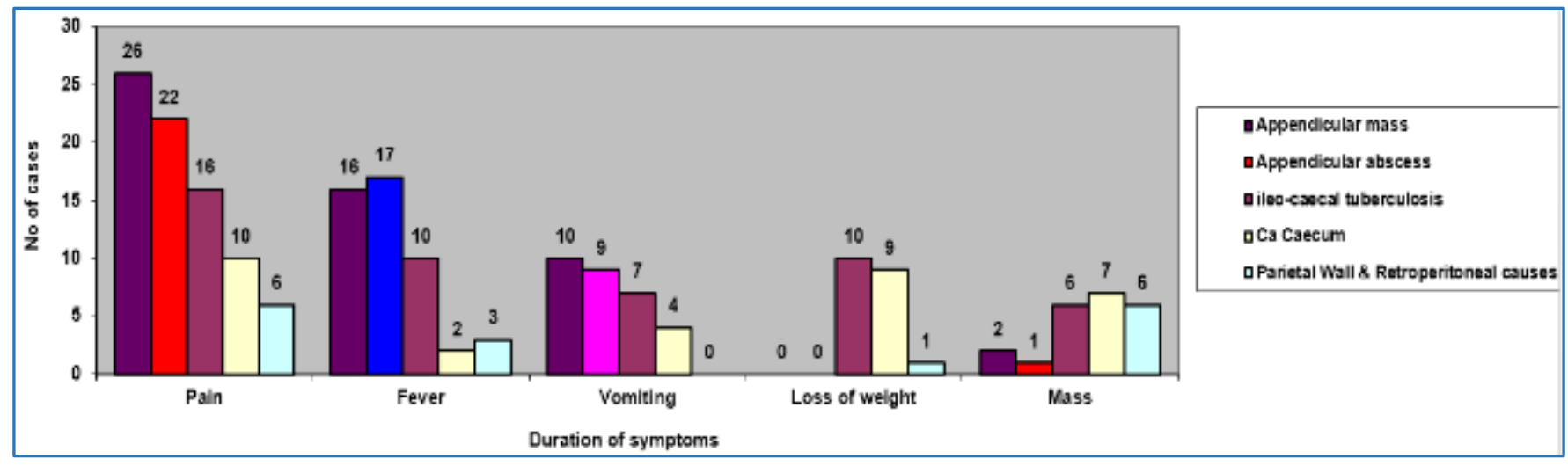

Fig. 6: Duration of Symptoms

Appendicular pathology patients are associated with pain, fever and vomiting. Majority of ileo-caecal tuberculosis patients are associated with fever and loss of weight and loss of appetite. Majority of carcinoma caecum patients had pain and mass. 


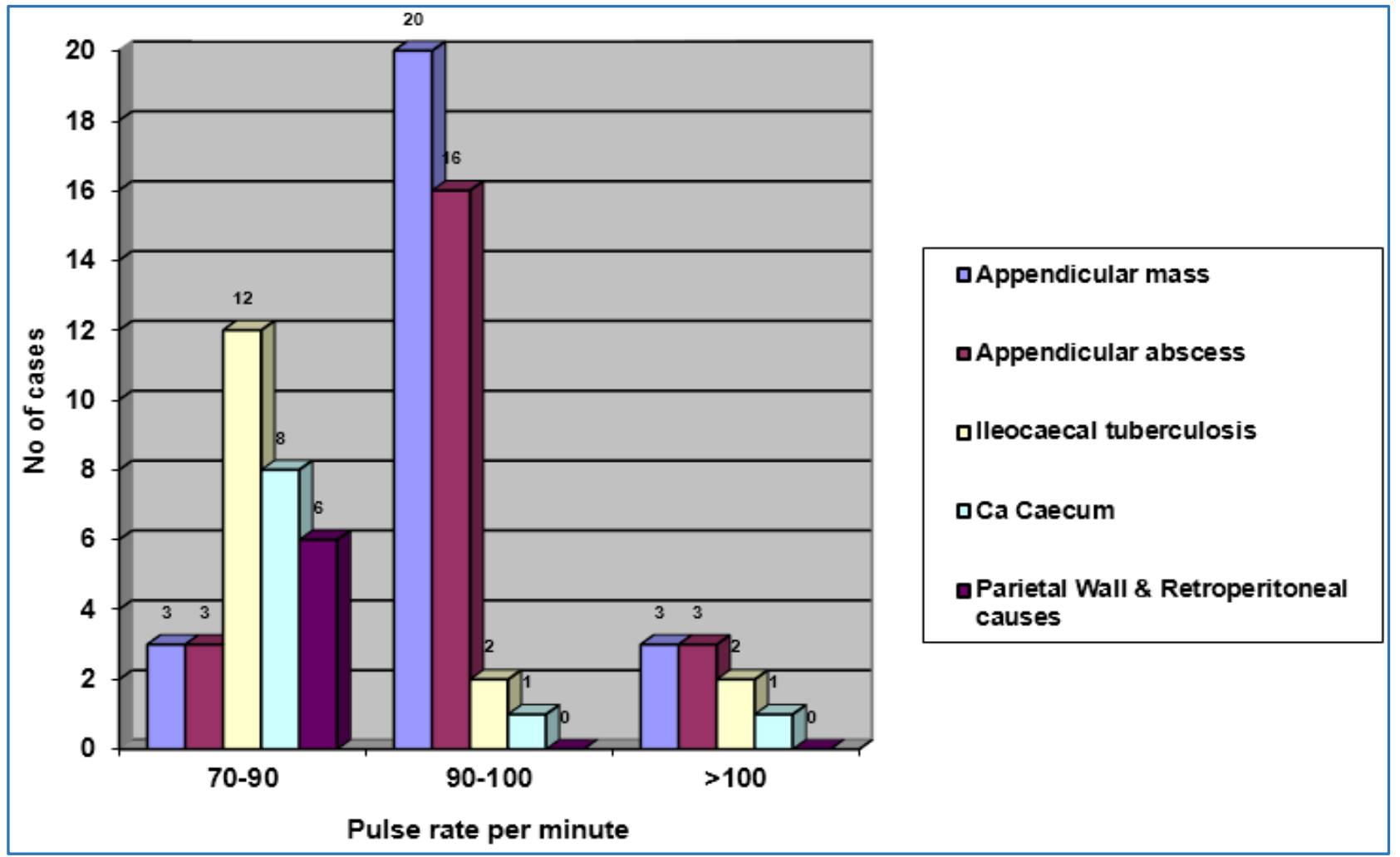

Fig. 7: Pulse Rate at Admission

Majority of appendicular pathology patients had tachycardia (90-100/min) at admission.

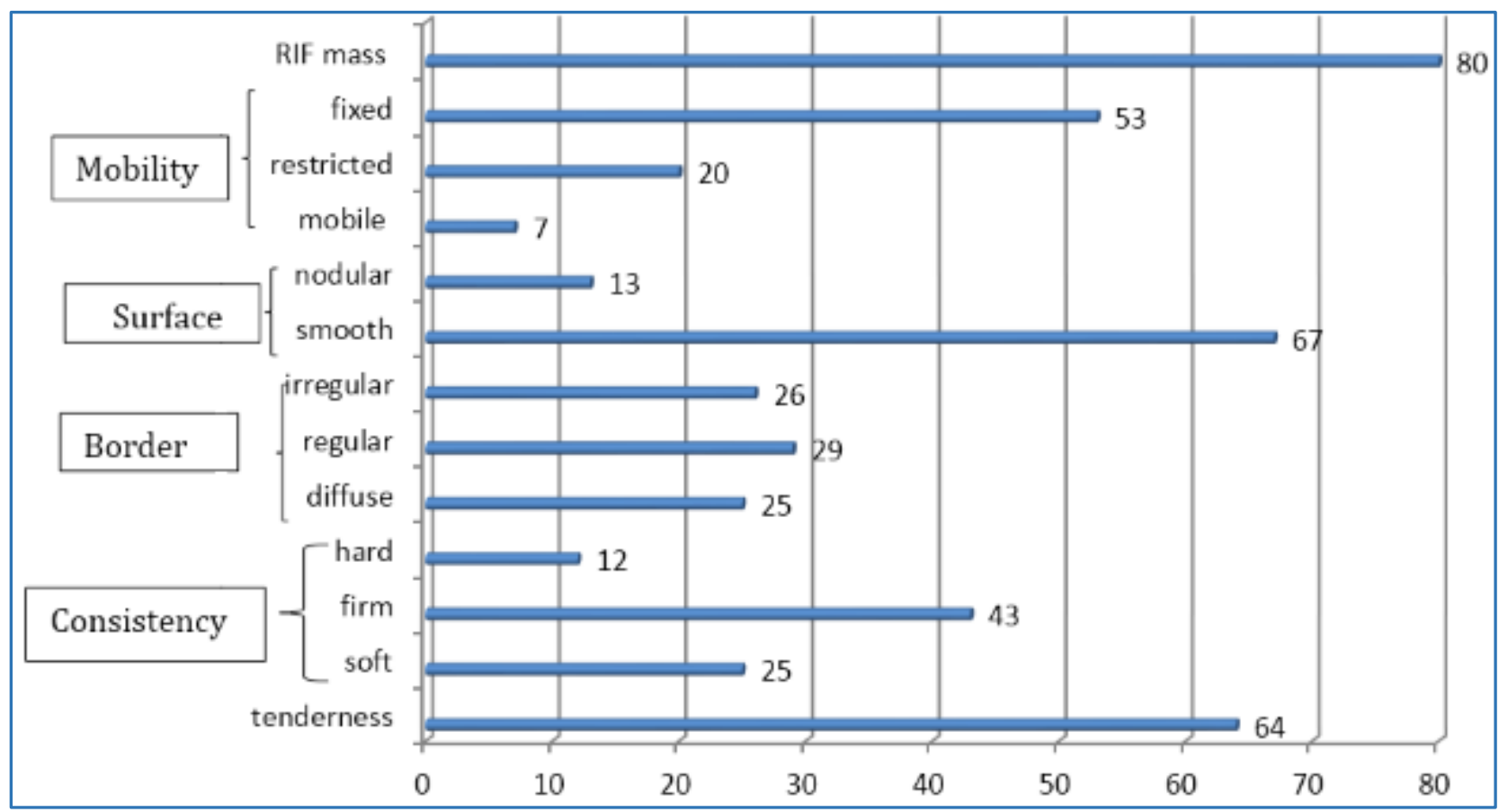

Fig. 8: Clinical Findings

All cases included in this study had a mass.

Appendicular abscess was soft in consistency with diffuse borders and smooth surface and fixed mass. Appendicular mass was firm in consistency with regular border, smooth surface and fixed mass. Ileo-caecal tuberculosis was firm in consistency with irregular border, smooth or nodular surface and a mobility restricted mass. Carcinoma caecum had a hard mass, irregular border, smooth or nodular surface, restricted mobility and fixed in advanced stage. 


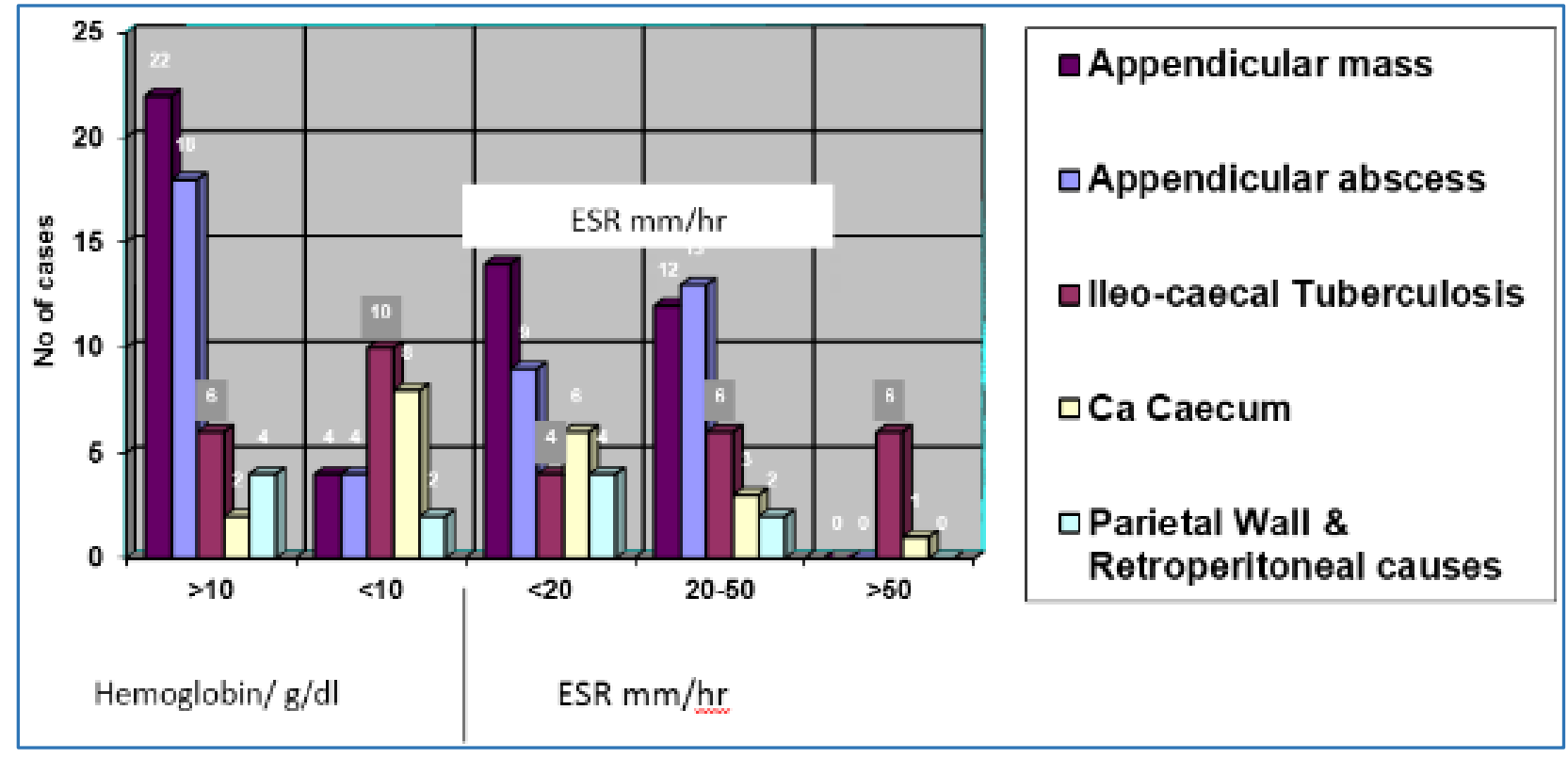

Fig. 9: Haemoglobin \& ESR

In our study $35 \%$ of the patients had Haemoglobin less than $10 \mathrm{gm} / \mathrm{dl}$. Majority of ileo-caecal tuberculosis and carcinoma caecum patients had haemoglobin less than $10 \mathrm{mg} / \mathrm{dl}$; $46 \%$ of patients had ESR less than $20 \mathrm{~mm} / \mathrm{hour}$; $45 \%$ of the patients had ESR 20- $50 \mathrm{~mm} /$ hour; $9 \%$ of the patients had ESR greater than $50 \mathrm{~mm} /$ hour.

Among 16 patients of ileo-caecal tuberculosis, 6 of them had marked elevation of ESR and one carcinoma caecum associated with ileo-caecal tuberculosis had high ESR.

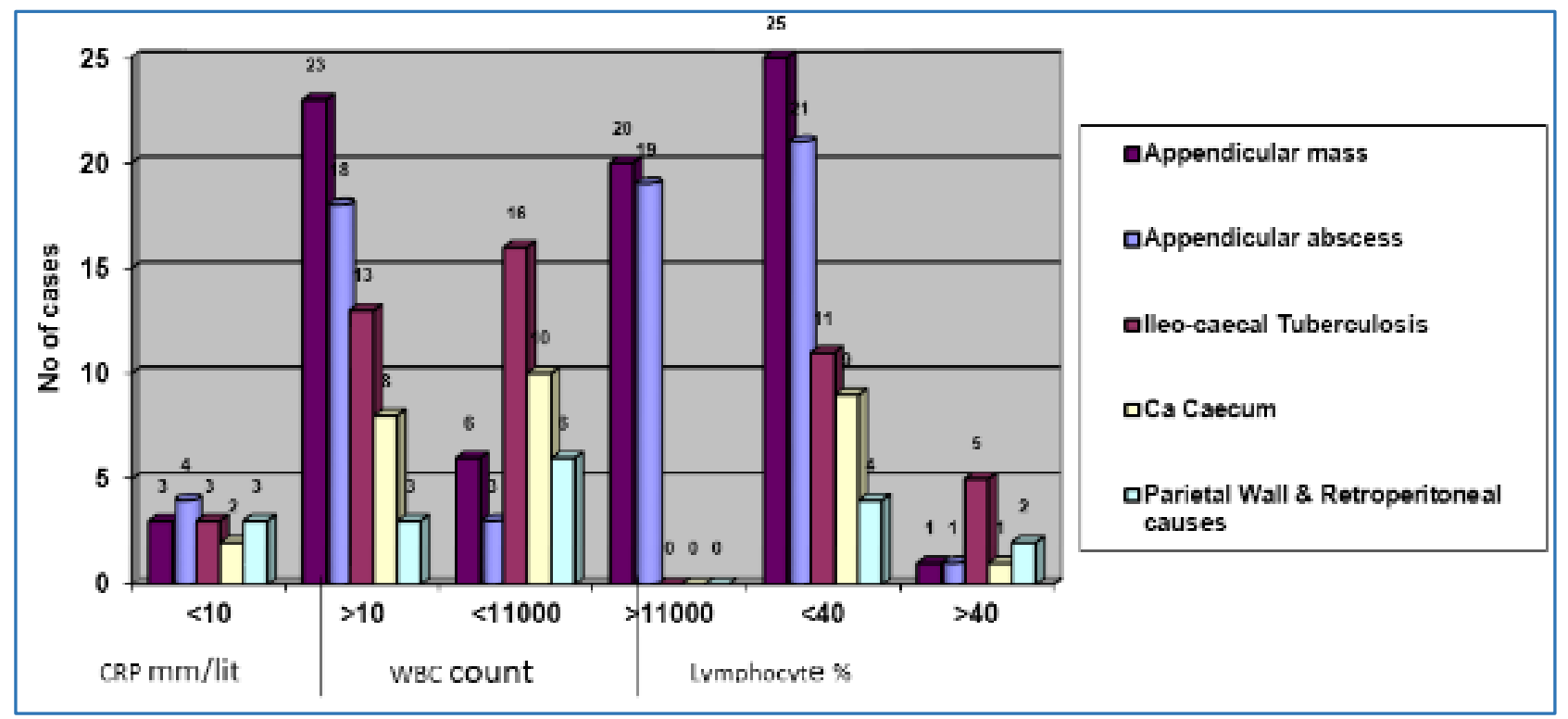

Fig. 10: CRP \& Total Leucocyte Count \& Lymphocyte Percentage

In our study $85 \%$ of the appendicular pathology patients had high CRP levels; $81 \%$ of appendicular pathology patients had leucocytosis ( $>11,000$ cells $\left./ \mathrm{mm}^{3}\right) ; 41 \%$ of tuberculosis associated patients had lymphocytosis. 


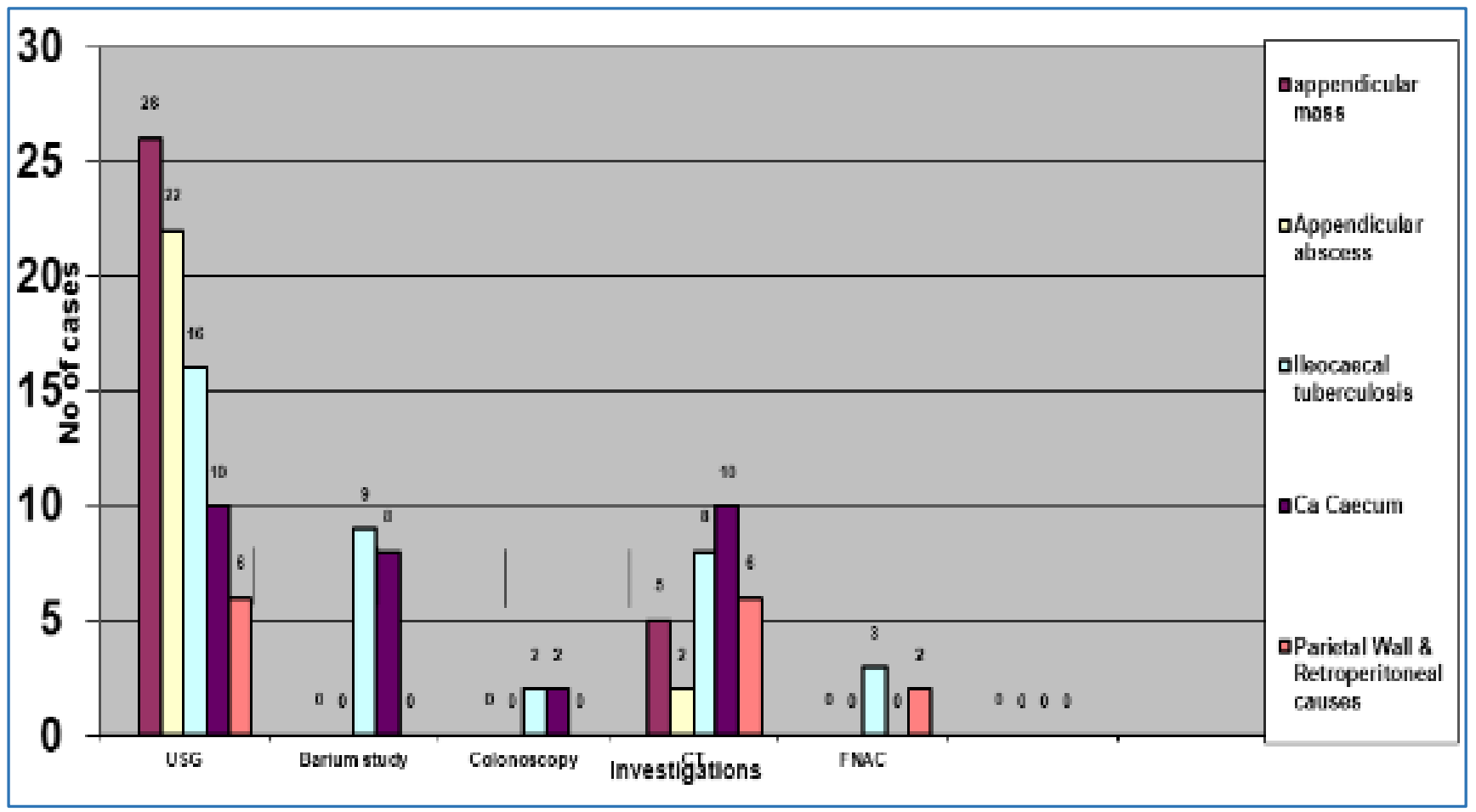

Fig. 11: Investigations

In our study, USG abdomen and pelvis was done for all patients and most of them were diagnosed correctly. Barium study done for (9) ileo-caecal tuberculosis patients and carcinoma caecum (8) patients and all of them were diagnosed correctly. Colonoscopy done for two ileocaecal tuberculosis and two carcinoma caecum patients. USG/CT guided FNAC done for three ileo-caecal tuberculosis patients and FNAC done for two desmoid tumour patients. CT done for 31 patients in various conditions and all of them were correctly diagnosed.

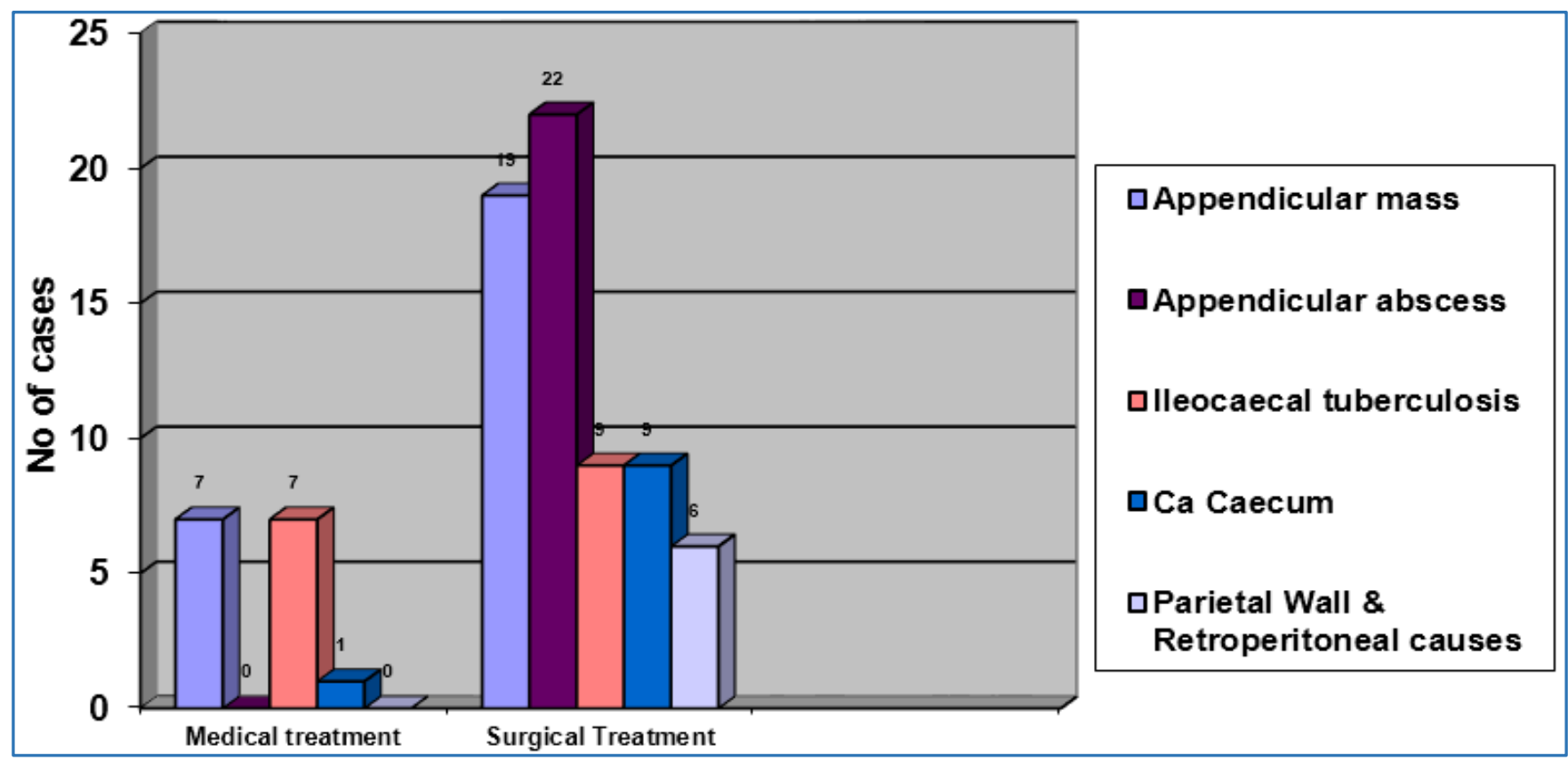

Fig. 12: Mode of Treatment

In our study $81 \%$ of patients are treated surgically; $19 \%$ of patients are treated conservatively. Conservatively treated seven appendicular mass patients did not come for interval appendicectomy. Seven ileo-caecal tuberculosis patients treated conservatively and one advanced carcinoma caecum patient was treated with palliative chemotherapy. 


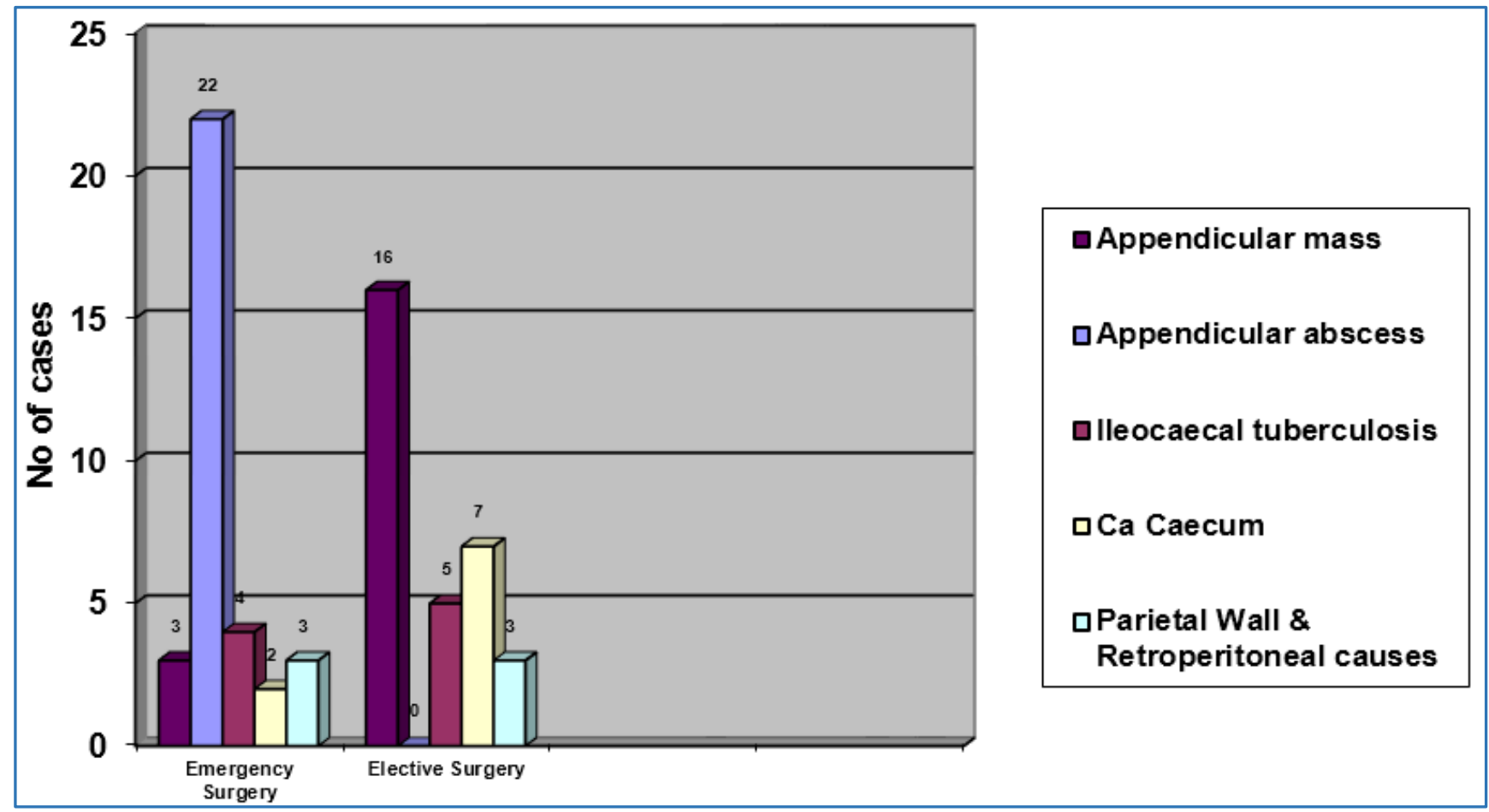

Fig. 13: Mode of Surgery

Among surgically treated 19 appendicular mass patients, 16 patients were treated with interval appendicectomy and 3 patients were treated with emergency appendicectomy. In 22 appendicular abscess patients, 14 patients were treated with emergency appendicectomy and 7 patients were treated with interval appendicectomy following extraperitoneal abscess drainage, one patient was treated by extraperitoneal drainage alone. Among surgically treated 9 patients of ileo-caecal tuberculosis, 4 patients were treated by emergency procedures following acute presentation and 5 patients were treated by elective procedures after initiating ATT. Among surgically treated 9 carcinoma caecum patients, 7 were treated with elective procedures and 2 patients were treated by emergency procedures for acute presentation.

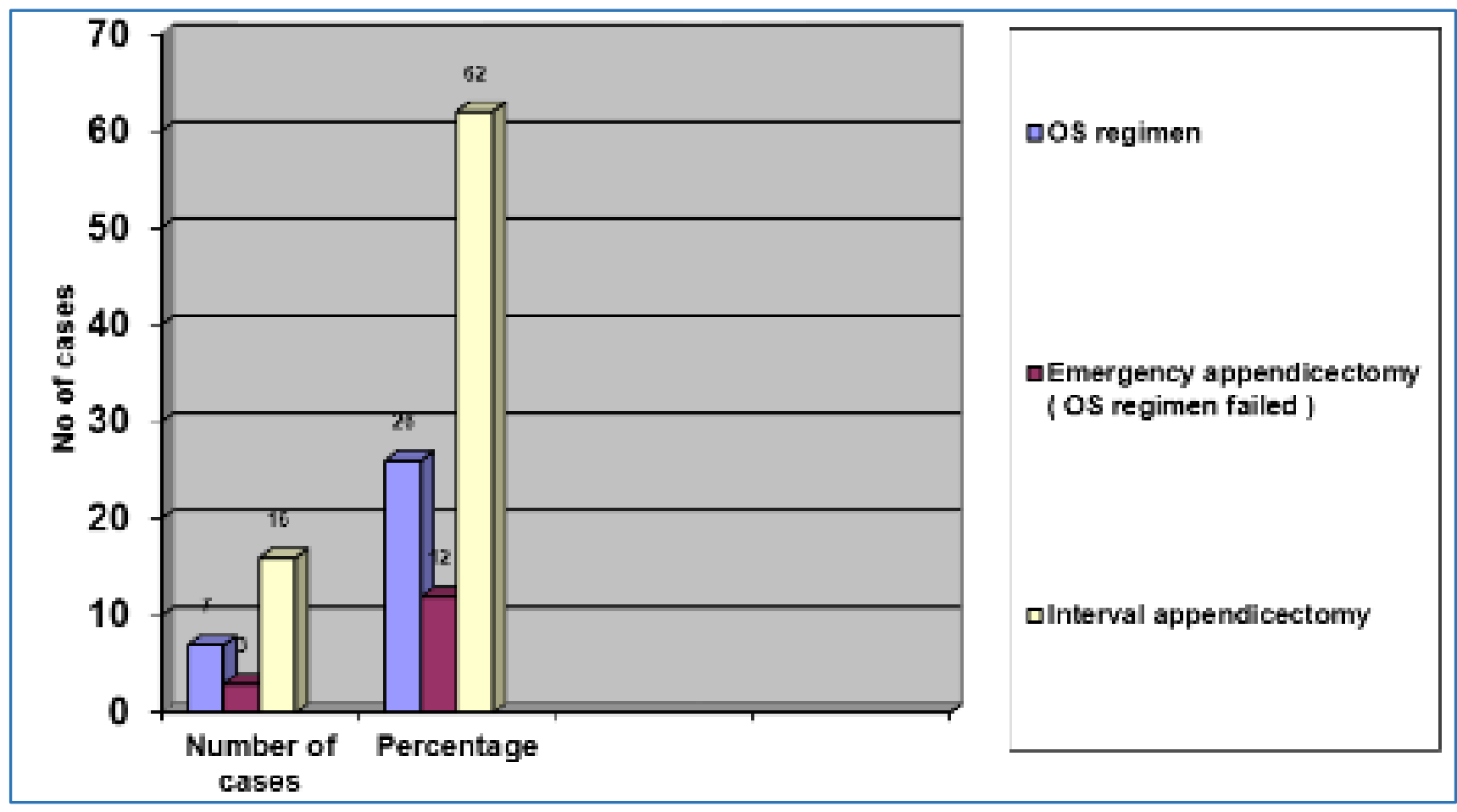

Fig. 14: Mode of Treatment for Appendicular Mass

Among conservatively treated 26 appendicular mass patients, 23 patients responded to Oschner-Sherren's regimen (88\%); $12 \%$ of the patients did not respond to Oschner-Sherren's regimen were taken for emergency surgery. 


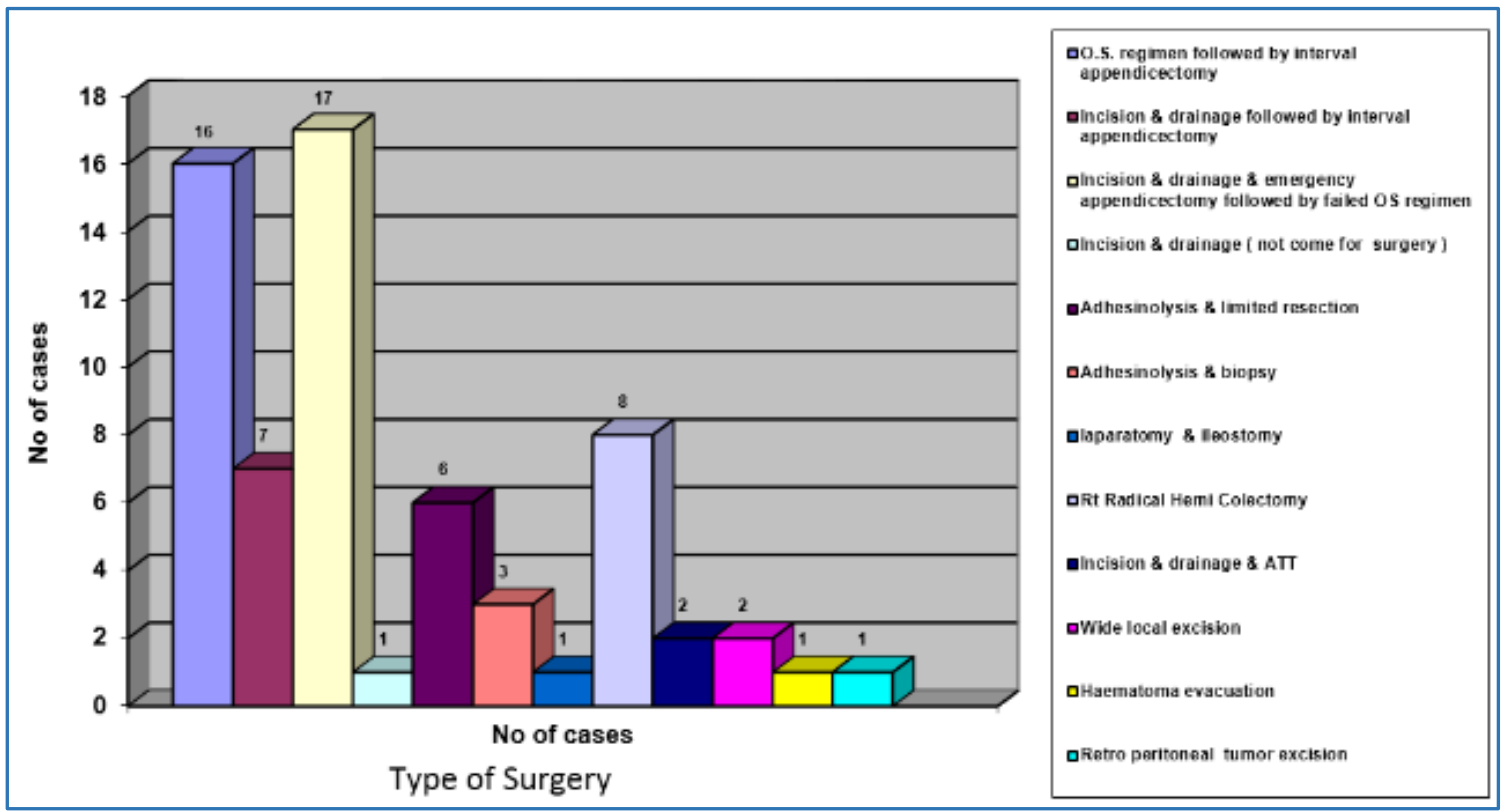

Fig. 15: Various Types of Surgeries

Among surgically treated 19 patients with appendicular mass, 3 cases were emergency appendicectomy, 16 cases were interval appendicectomy.

Among 22 patients with appendicular abscess, 14 patients were treated with laparotomy and drainage with emergency appendicectomy and 7 patients treated with laparotomy and drainage followed interval appendicectomy and one patient treated with laparotomy and drainage did not turned back for interval appendicectomy.

Among surgically treated 9 ileo-caecal tuberculosis patients, 3 patients are treated with laparotomy and adhesiolysis with biopsy, another 5 patients are treated with laparotomy and adhesiolysis with limited resection, one ileal perforation patient was treated with emergency laparotomy and limited resection.

Among surgically treated 9 carcinoma caecum patients, 7 patients are treated with right radical hemicolectomy electively and emergency right radical hemicolectomy was done for one patient who presented with acute right colo-colic intussusception, another one perforated patient was treated with emergency laparotomy and ileostomy. Laparotomy and excision biopsy was done for retroperitoneal Schwannoma patient. Wide excision and parietal wall reconstruction was done for parietal wall desmoid tumour patients. Psoas abscess patients were treated with extraperitoneal drainage and ATT. Rectus sheath haematoma patient was treated by evacuation.

\section{DURATION OF INPATIENT PERIOD (DAYS)}

In our study $41 \%$ of patients had in-patient stay of less than 10 days; $59 \%$ of patients stayed for more than 10 days, these included surgically treated ileo-caecal tuberculosis and carcinoma caecum cases. Most of the interval appendicectomy patient's hospitalisation is more than 10 days.

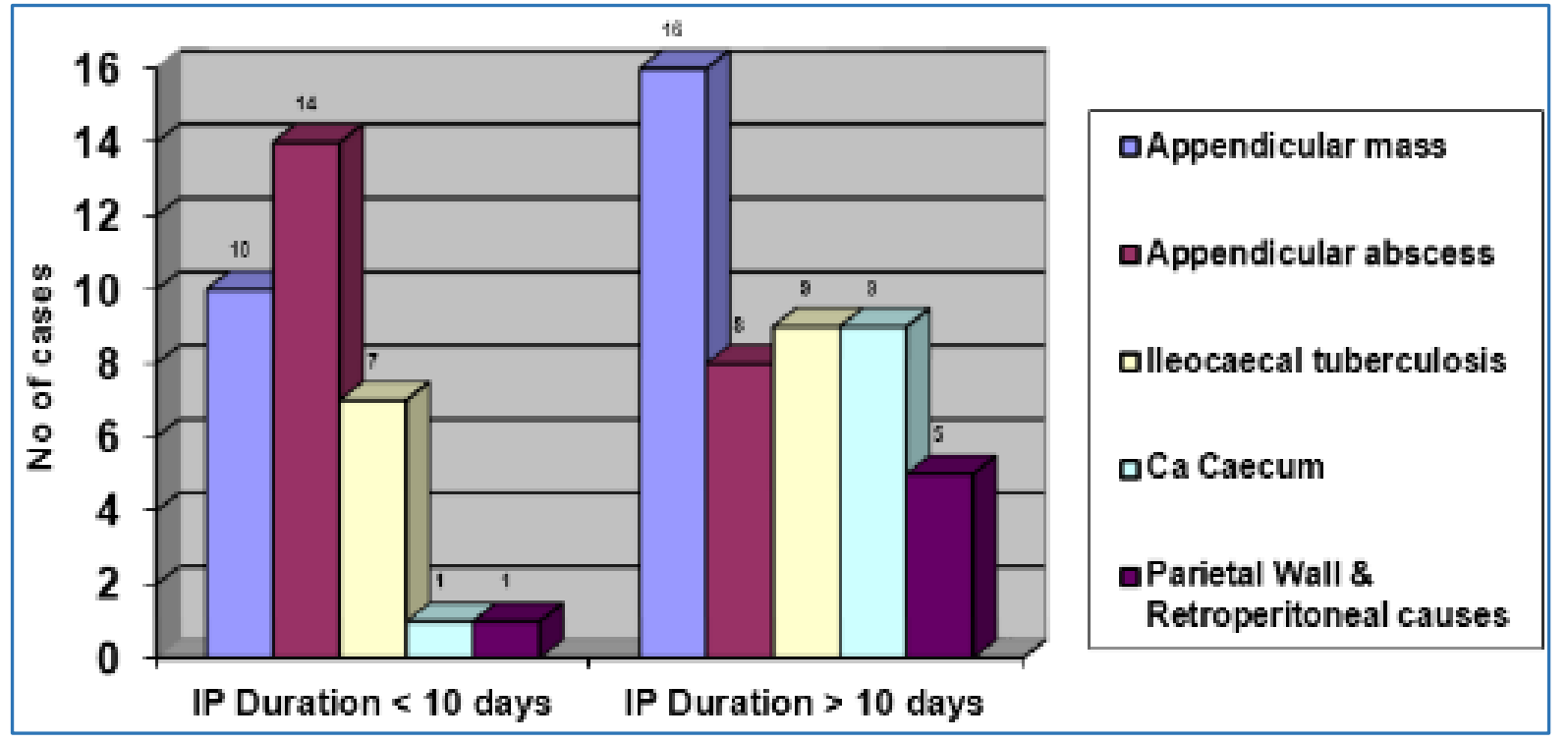

Fig. 16: Duration of Hospitalisation 


\section{POSTOPERATIVE COMPLICATIONS}

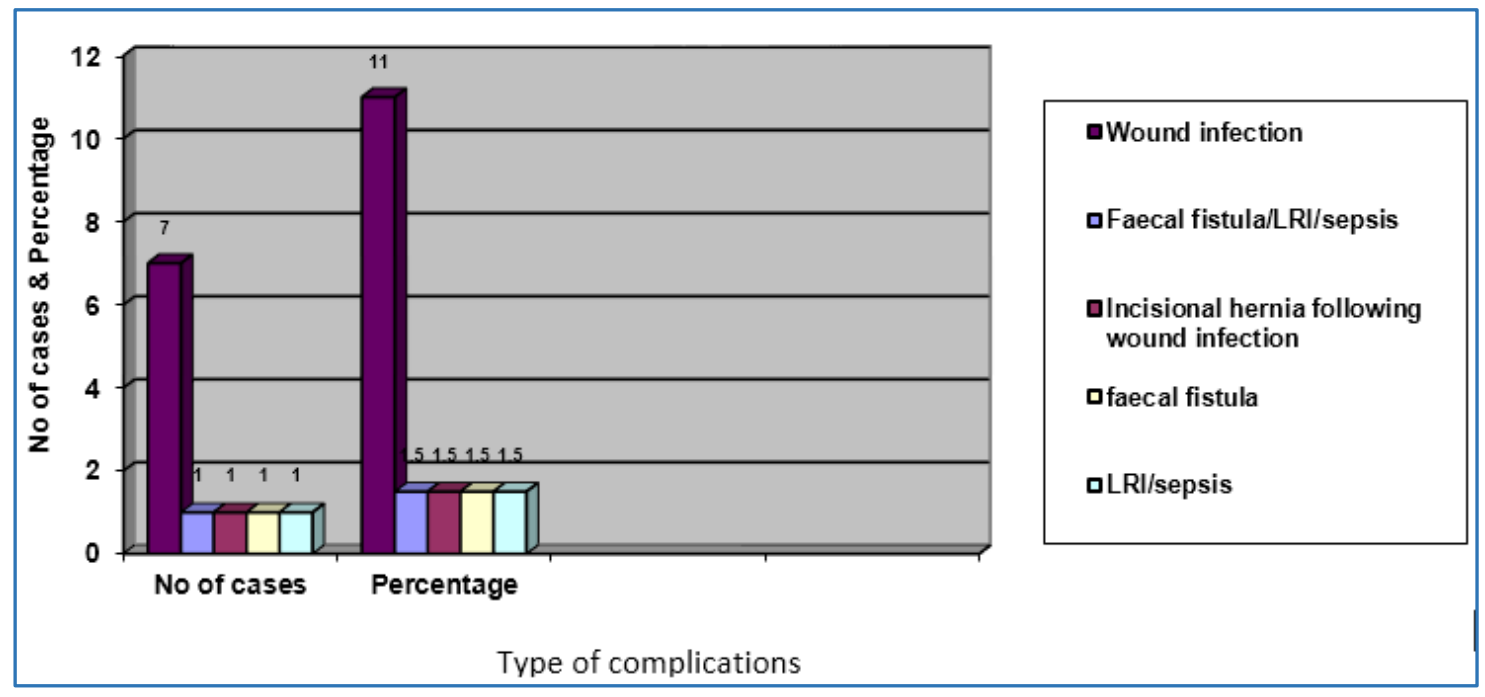

Fig. 17: Various Complications

Commonest post-operative complication is wound infection, commonly associated with emergency appendicectomy in either appendicular mass or abscess. One case of faecal fistula is associated with appendicular abscess; another case is associated with ileocaecal tuberculosis. One case of incisional hernia followed an emergency appendicular abscess drainage procedure.

\section{POSTOP FOLLOWUP IN SURGICAL PATIENTS}

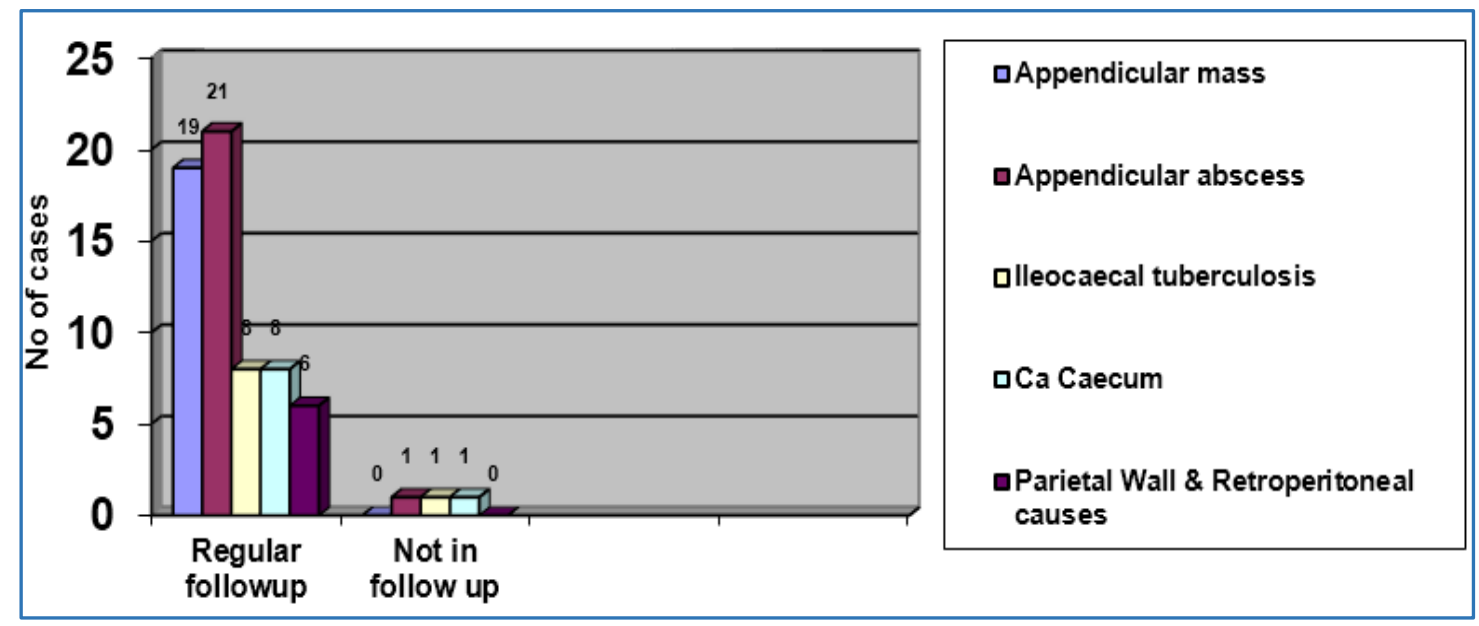

Fig. 18: Followup

In our study $95 \%$ of post-operative patients are on regular followup. Surgically treated 8 and conservatively treated 7 ileo-caecal tuberculosis patients, abdominal tuberculosis associated one carcinoma caecum patient and 2 psoas abscess patients are on regular follow-up with ATT (DOTS-I). One ileo-caecal tuberculosis, one carcinoma caecum patient expired in post-operative period out of surgically treated 65 patients.

\section{DISCUSSION}

Mass in the right iliac fossa is one of the common entity in surgical practice. Evaluation of right iliac fossa mass is essential for management and outcome.

In our study of "Evaluation of Right Iliac Fossa Mass" was made at our institution Chengalpattu Medical College from October 2010 to October 2012; 80 cases of right iliac fossa mass were studied. Among 80 cases, majority of the cases are from rural, low socio-economic group. In our study the commonest cause of right iliac mass is appendicular pathology (Either appendicular mass-32.5\% or appendicular abscess$27.5 \%)$ followed by ileo-caecal tuberculosis-20\% and carcinoma caecum- $12.5 \%$ other rare causes $-7.5 \%$.

\section{APPENDICULAR PATHOLOGY}

In our study, appendicular pathology (Either appendicular mass or appendicular abscess) constituted $60 \%$. According to Schwartz' principles of surgery, male-to-female ratio in appendicular pathology is $1.2-1.3: 1$, in our study male-tofemale ratio is 1.1:1, which is comparable.

In our study of appendicular pathology $100 \%$ of patients had pain and $69 \%$ had fever, $40 \%$ had vomiting and anorexia, $88 \%$ had tachycardia and common age group is $10-60$ years 
(98\%.36) Okafor PI et al. said common symptoms in appendicular mass and appendicular abscess are pain, fever, dyspepsia, anorexia and tender palpable RIF mass and the commonest age group is $2^{\text {nd }}$ to $6^{\text {th }}$ decade, which is comparable in our study.

Majority of patients had symptoms for less than one month duration and only a few patients had abdominal mass as a symptom, and most of appendicular pathology patients are not anaemic, had mild elevation of ESR, and raised heart rate in $88 \%$ of cases. Oliak. ${ }^{3} \mathrm{D}$ et al. said factors at admission, pain, fever, tachycardia like symptoms and blood investigations had $86 \%$ sensitivity and $58 \%$ specificity, which is comparable.

In our study $85 \%$ of patients had elevated C-reactive protein and $81 \%$ had leukocytosis. Gronross. ${ }^{4} \mathrm{JN}$ et al. said leukocytosis is an early marker in appendicular pathology and raised CRP is a late marker and if leucocyte count and CRP are normal that condition is unrelated to appendicular mass or abscess, which is comparable. Gronross JM. ${ }^{5}$ said that appendicular mass or abscess can be ruled out in an adult patient if total leucocyte count and CRP are within normal limits.

In our study, $88 \%$ of appendicular mass patients responded to Oschner-Sherren's regimen. Among 26 appendicular mass patients, 3 patients (12\%) failed conservative management and were taken up for emergency appendicectomy. All conservatively treated patients are advised interval appendicectomy, 62\% patients (16) underwent interval appendicectomy and $26 \%$ of patients (7) did not come back for interval appendicectomy.

Erdogan D. 6 et al. said Oschner-Sherren regimen for appendicular mass is safe and interval appendicectomy is advisable, which favours our study.

In our study, among 22 appendicular abscess patients, emergency extraperitoneal abscess drainage was done for all, along with drainage 14 patients (64\%) underwent emergency appendicectomy and 7 patients (32\%) underwent interval appendicectomy after 3 months, and 1 patient (4\%) did not come back for interval appendicectomy. Zarba. ${ }^{7}$ et al. said emergency appendicectomy with abscess drainage is the mode of treatment for appendicular abscess with low morbidity and minimal hospitalization and minimal health cost and postoperative morbidity only $9 \%$. Out of $9 \%$, wound infection is $75 \%$ and wound dehiscence is $25 \%$, which is comparable.

Among 48 appendicular pathology patients 7 patients were treated conservatively, 1 patient treated with abscess drainage only, 23 patients treated with interval appendicectomy and 17 patients treated with emergency appendicectomy. Among 17 patients treated with emergency appendicectomy 6 patients developed wound infection, 1 patient developed faecal fistula, among those 6 patients who developed wound infection, 1 patient developed incisional hernia.

All emergency appendicectomy patients HPE report was acute appendicitis and for all interval appendicectomy patients HPE report was chronic appendicitis. Most of the postoperative complications occurred in emergency appendicectomy done for appendicular mass or appendicular abscess. Interval appendicectomy planned for either conservatively treated appendicular mass patients or post appendicular abscess drainage patients increases duration of hospital stay and cost of health, but interval appendicectomy produced very minimal post-operative complications. Hurme T. ${ }^{8}$ et al. said emergency appendicectomy done for appendicular abscess in acute phase produced more complications, abscess drainage followed by interval appendicectomy healed well without complications, which is comparable. Eriksson S. ${ }^{9}$ et al. said that interval appendicectomy and emergency appendicectomy for acute appendicitis had the same complication rates.

Lasson A. ${ }^{10}$ et al. said that percutaneous aspiration followed by interval appendicectomy for appendicular abscess is the best treatment. Recurrent appendicitis is common if abscess drainage done without interval appendicectomy. Postoperative complications are least in interval appendicectomy, which is comparable.

Conservatively treated appendicular mass patients and appendicular abscess patients treated by surgical drainage without appendicectomy are prone for recurrent appendicitis (20\%) when compared to general population (15\%) with no significant difference, so interval appendicectomy is controversial.

Hoffman. ${ }^{11}$ et al. said only $20 \%$ of patients developed recurrence following conservative treatment of appendicular mass. Among 20\%, most of the recurrence (66\%) occurred within 2 years. Corefield L et al. ${ }^{12}$ said more than $50 \%$ of the surgeons do interval appendicectomy anticipating the recurrence rate of $10 \%-25 \%$ and complication rate of $23 \%$. So a randomized control trial is needed for evaluation of this issue.

In our institution, conservatively treated 16 appendicular mass patients and surgically drained 7 appendicular abscess patients underwent interval appendicectomy (74\%). Conservatively treated $26 \%$ patients did not come for follow-up and surgery.

\section{ILEO-CAECAL TUBERCULOSIS}

Abdominal tuberculosis is one of the important gastroenterological problem in developing countries, newer drugs and advanced socio-economic status in developed countries controlled the tuberculosis, but majority of the under developed countries had huge problem in prevention of tuberculosis, abdominal tuberculosis is a common problem in our country also. Majority of the abdominal tuberculosis patients treated conservatively in our institution.

Ileo-caecal tuberculosis constituted about $30 \%$ of abdominal tuberculosis. Commonly affected age group is 2550 years, common symptoms are pain, fever, vomiting, weight loss and anorexia. In our institution $20 \%$ of RIF mass are due to ileo-caeacal tuberculosis, $56 \%$ are females and $44 \%$ are males. Most of patients had symptoms for more than one month, $56 \%$ of patients had symptoms for 1-3 months. Commonest symptoms are pain, followed by fever and loss of weight. Majority of the patients had firm, mobile or restricted mobile, irregular mass per abdomen. $62.5 \%$ of patients are anaemic, more than $75 \%$ of patients had elevated ESR. Sharp J E. 13 et al said $95 \%$ of the patients had elevated ESR, which is comparable in our study.

In our study, among 80 patients, $20 \%$ (16 patients) had ileo-caecal tuberculosis. Among 16 patients (19\%), 3patients had positive Mantoux test and 2 patients (13\%) had Koch's lesion on chest radiography and 8 patients (50\%) had air-fluid level, one patient had pneumoperitoneum on abdomen radiography. $80 \%$ of ileo-caecal tuberculosis had elevated CRP. 
CRP titres are used to assess the treatment response of the disease. $30 \%$ of the patients had lymphocytosis and $44 \%$ of the patients were treated conservatively.

USG is an initial investigation for the diagnosis of ileocaecal tuberculosis. In inconclusive cases CT, barium study, colonoscopy with biopsy, USG/CT guided FNAC like other mode of investigations were done. Laparoscopy is the useful recent modality for diagnostic and therapeutic purposes in abdominal tuberculosis. Balthazar EJ. ${ }^{14}$ et al. said barium study with CT conjunction is useful for the diagnosis of the location, extent and mesenteric involvement of ileo-caecal tuberculosis lesions. Uzun Koy. ${ }^{15} \mathrm{~A}$ et al. said USG guided FNAC is a reliable investigation for ileo-caecal tuberculosis, which is comparable.

Rai S. ${ }^{16}$ et al. said that common complaints are pain and weight loss, clinical features are non-specific, and consistent laboratory findings are elevated CRP and low $\mathrm{Hb} \%$ in more than $90 \%$ of the patients and Mantoux test was positive in $22 \%$, which is comparable.

Immanuvel. ${ }^{17} \mathrm{C}$ et al said decreasing serum C-Reactive Protein titres in ileo-caecal tuberculosis is an useful indicator for treatment response; $62 \%$ of the patients had elevated serum CRP initially, after completion of ATT only $14 \%$ of the patients had raised CRP levels, which is comparable.

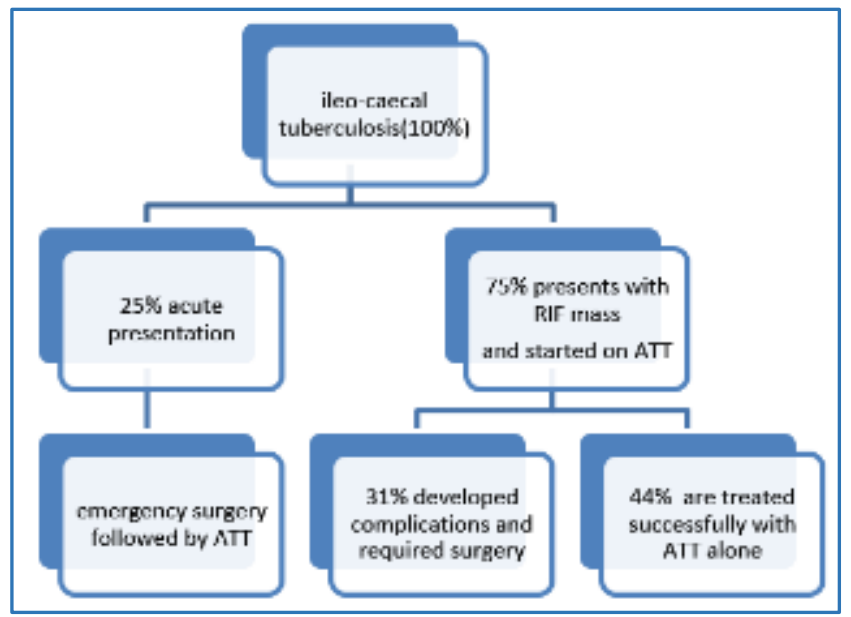

9 patients (50\%) underwent surgery with ATT in our institution. In our study 4 patients (44\%) underwent emergency surgeries before initiating ATT and 5 patients (56\%) underwent surgery after initiating ATT and had complications. Adhesiolysis, limited resection and anastomosis, right hemicolectomy and ileostomy like various procedures done for appropriate cases in our institution. All patients HPE report was ileo-caecal tuberculosis. More than $50 \%$ of the patient's hospital stay is greater than 10 days, 2 patients suffered from wound infection. Ileostomy with right hemicolectomy done ileal perforated patient expired with wound infection, LRI and sepsis. Most of the patients came for regular follow-up and are on ATT (DOTS-I).

Kosal' enikov. ${ }^{18}$ SO et al. said surgery is required for $91 \%$ of complicated abdominal tuberculosis patients. Commonly, right hemicolectomy, enterostomy, abscess drainage, excision of necrotic lymph nodes, adhesiolysis, formation of bowel bypass or anastomosis are required in appropriate patients. Early diagnosis with ATT and surgical procedures improved the outcome, which is comparable.

Prakash A. ${ }^{19}$ et al said ileo-caecal tuberculosis is common in 20-40 years of age and affected female to male ratio is 1.6:1.
Barium study is a useful investigation; $44 \%$ of patients developed sub-acute intestinal obstruction and $16 \%$ patients had acute intestinal obstruction. Bowel resection and by-pass procedures are required in $16 \%$ of patients, which is comparable.

Muneef MA. ${ }^{20}$ et al. said that incidence of ileo-caecal tuberculosis is $52 \%$ in females and $48 \%$ in males and mean age is 46 years. Commonest clinical symptoms are fever, pain abdomen, weight loss in $70 \%$ of the patients, mass per abdomen in $67 \%$, altered bowel habits in $39 \%$ of the patients and anorexia in $30 \%$ of the patients. Clinical signs are fever in $73 \%$ of the patients, ascites in $61 \%$ of the patients, mass abdomen $13 \%$ of the patients and doughy abdomen in $9 \%$ of the patients. Mantoux test is positive in $27 \%$ of patients, CT abdomen showed ascites, peritoneal lesions and enlarged nodes in $80 \%$ of the patients.

Biopsy taken in $61 \%$ of the patients, HPE reported positive in $97 \%$ of the patients. Significant percentage of the patients recovered with medical management alone, which is comparable.

\section{CARCINOMA CAECUM}

Colorectal carcinoma commonly occurs after $5^{\text {th }}$ decade, males are more prone than females and high prevalence rate is noted in high socio-economical group of population. In our study of RIF mass, $12.5 \%$ cases are due to carcinoma caecum and majority of the patients are in $6^{\text {th }}$ decade followed by $7^{\text {th }}$ and $5^{\text {th }}$ decade, male to female ratio is $3: 2$, most of the patients are from low socio-economical group.

Stock- C. ${ }^{21}$ et al. said carcinoma caecum is more prevalent in patients more than 50 years of age, affects males more than females. Colonic carcinoma prevalence is increased in $8^{\text {th }}$ decade, which is comparable.

Mohandas. ${ }^{22} \mathrm{KM}$ et al. said male sex is predominantly affected in colonic carcinoma and increased prevalence is noted in immigrants and urban population than rural Indians due to environmental and dietary habits, which is comparable.

Majority of patients had symptoms for more than 1 month, commonest symptoms are pain, loss of weight and mass per abdomen. All cases had hard mobile or fixed RIF mass; $80 \%$ of carcinoma caecum patients were anaemic and had mild elevation of ESR. Among 10 cases of carcinoma caecum marked elevation of ESR is present in one case that had associated abdominal tuberculosis (10\%).

$\mathrm{Li} \mathrm{J} \mathrm{N.}{ }^{23}$ et al. said that carcinoma colon is a disease of the old age associated with anaemia and palpable mass per abdomen, right sided colonic malignancies decreased and left sided colonic malignancies are increased in current studies.

Sadahiro. ${ }^{24} \mathrm{~S}$ et al. said $26 \%$ of women and $21 \%$ of men with right sided colonic carcinoma have haemoglobin less than 10 grams percentage, which is comparable.

Forslund. ${ }^{25} \mathrm{~A}$ et al. said that low haemoglobin and elevated ESR, CEA, ALP is present in colonic carcinoma. Outcome of the patients with marked elevation of ESR and severe anaemia was poor, which is comparable.

In our study, $20 \%$ of patients had significant elevation of serum CRP titres.

Gur T.26 et al. said colonic malignancy patients had significant elevation of CRP and Chung Y C. ${ }^{27}$ et al. said outcome of the patients with elevated serum CRP was poor and onethird of the patients with advanced disease had markedly elevated CRP titres, which is comparable. 
USG abdomen and pelvis was done for all patients (100\%), barium study was done for 8 patients, CT scan abdomen and pelvis was done for all patients. CT scan revealed RIF mass in 8 patients, right sided colo-colic intussusception in one patient and pneumoperitoneum in another one patient. Colonoscopy was done for $20 \%$ of the patients.

Storm E. ${ }^{28}$ et al. said that barium study has $91 \%$ sensitivity for diagnosis of colonic malignancies, which is comparable.

In our study, $90 \%$ of the patients are treated surgically in our institution. Among 10 patients, majority of the patients (7) were treated by right radical hemicolectomy (70\%) electively and one patient $(10 \%)$ with right colo-colic intussusception underwent emergency right radical hemicolectomy with primary anastomosis. Another one patient with ileal perforation, underwent emergency ileostomy and expired post-operatively due to LRI with septicemia. All other patients came for regular follow-up and were on anti-cancer chemotherapy. One patient $(10 \%)$ with advanced carcinoma caecum was treated with palliative chemotherapy. For all postoperative patients HPE reports revealed various types of adenocarcinoma caecum. Among 10 carcinoma caecum patients, one patient (10\%) had associated abdominal tuberculosis and was started on ATT prior to chemotherapy.

Herfath. $^{29} \mathrm{C}$ et al. said that treatment of carcinoma caecum and ascending colon presenting with obstruction, the treatment of choice was right hemicolectomy with ileostomy and transverse colostomy, which is comparable in our study.

\section{PARIETAL WALL AND RETROPERITONEAL CAUSES}

In our study, both the parietal wall desmoid tumour patients are females in reproductive age group. USG, CT confirmed the parietal wall lesion, FNAC and excision biopsy followed by surgery confirmed the diagnosis.

Aissa. ${ }^{30} \mathrm{~A}$ et al. said that desmoid tumour is common in anterior abdominal wall, more prevalent in pregnancy and post-partum period and associated with hormonal influence. USG, CT, MRI and post-operative excisional biopsy reports are confirmatory investigations, which is comparable.

Etiology of both the psoas abscess patients was tuberculosis, both underwent extra-peritoneal drainage with ATT.

Villar F.31 C et al. said $50 \%$ of the psoas abscess is associated with skeletal tuberculosis, which is comparable in our study.

In our study, one rectus sheath haematoma patient presented as RIF mass, surgical evacuation of the haematoma was done as the conservative management failed.

Rajagopal. ${ }^{32}$ et al. said that abdominal pain in parietal wall haematoma is a rare entity and is treated conservatively and rarely require surgical intervention, which is comparable.

In our study, one retroperitoneal Schwannoma patient presented as RIF mass which was diagnosed by USG/CT/USG guided core needle biopsy. Surgical excision was done.

Rai BR. ${ }^{33}$ et al. said that pelvic Schwannoma presented as RIF mass and right sciatica, which is comparable.

In our study USG abdomen and pelvis is done for all cases and RIF mass was diagnosed in more than $95 \%$ of the patients. In inconclusive cases, various investigations like CT, barium study, colonoscopy, USG guided FNAC were done.
According to the Sabiston text book of surgery USG abdomen had $85 \%$ sensitivity and $90 \%$ specificity for diagnosis of appendicular pathology, which is comparable.

Millard FC. ${ }^{34}$ et al. said USG abdomen correctly diagnosed $97 \%$ of RIF masses, so the investigation of choice in RIF mass is USG abdomen, which is comparable.

Jain R. ${ }^{35}$ et al. said that sonographic features of abdominal tuberculosis thickened mesentery and lymphadenopathy, dilated small bowel loops and ascites were diagnosed in $98 \%$ of the patients, which is comparable.

Martinez. ${ }^{36}$ Ares D et al. said that USG abdomen is $79 \%$ sensitive and $92 \%$ specific for the diagnosis of colonic carcinoma, which is comparable.

In our study, overall post-operative morbidity is $17 \%$ and mortality is $3 \%$. Common post-operative complication is wound infection. Most of the post-operative complications are treated conservatively.

\section{CONCLUSION}

- Right iliac fossa mass was common in 20 to 50 years of age group.

- Overall incidence was more common in males as compared to females (1.1:1).Appendicular pathology and Carcinoma caecum was more common in males as compared to females. Ileo-caecal tuberculosis was more common in females.

- The diseases were more in people from low socio economic status and the commonest symptom was pain in abdomen.

- Appendicular pathology (60\%) either in the form of appendicular mass $(32.5 \%)$ or appendicular abscess $(27.5 \%)$ were the commonest cause of mass in the right iliac fossa. Ileo-caecal tuberculosis (20\%), carcinoma caecum $(12.5 \%)$ was the other common causes of mass in the right iliac fossa.

- Ultrasound abdomen was the essential investigation and it had a sensitivity of greater than $95 \%$.

- Normal levels of serum CRP titer essentially ruled out appendicular pathology. Serial titers were helpful in assessing the treatment response of ileo-caecal tuberculosis and in prognosis of carcinoma caecum.

- In patients with appendicular mass, initial conservative management followed by interval appendicectomy had better results with minimal complications.

- In patients with appendicular abscess, abscess drainage combined with appendicectomy in the same procedure, had high morbidity compared to patients who underwent interval appendicectomy following abscess drainage.

- A $44 \%$ of the patients with ileo-caecal tuberculosis were managed conservatively with anti-tubercular therapy (DOTS-I). Surgery was required in another $56 \%$ of the patients, of which $25 \%$ of the patients presented with acute complications needing immediate surgery; $31 \%$ of the patients presented with sub-acute intestinal obstruction due to adhesions and strictures following the initiation of anti-tubercular therapy, which later required surgical intervention.

- An $80 \%$ of the patients with carcinoma caecum underwent successful surgical resection; $20 \%$ of the patients presented with acute surgical problem requiring immediate surgery; $10 \%$ of the patients presented with advanced disease. 
- Most of the parietal wall and retroperitoneal conditions were treated surgically.

- Early evaluation and intervention is needed to improve the patient's outcome and to reduce the morbidity and mortality.

\author{
LIST OF ABBREVIATIONS \\ ADA - Adenosine deaminase \\ ALP - Alkaline phosphatase \\ ATT - Antitubercular treatment \\ Ca - Carcinoma \\ CEA - Carcinoembryonic antigen \\ CT - Computerised Tomography. \\ CRP - C-Reactive protein \\ DVT - Deep vein thrombosis \\ EGFR - Epidermal growth factor receptor \\ FNAC - Fine needle aspiration cytology \\ 5-FU - 5-Fluro uracil \\ HIV - Human immunodeficiency virus \\ HPE - Histopathological examination \\ LIF - Left iliac fossa \\ LRI - Lower respiratory tract infection \\ MRI - Magnetic resonance imaging \\ NSAID - Non-steroidal anti-inflammatory drugs. \\ O-S - Ochsner-Sherren regimen \\ PCR - Polymerase chain reaction \\ PET - Positron emission tomography \\ PPD - Purified protein derivatives \\ RIF - Right iliac fossa \\ Tc99 - Technetium 99 \\ TC - Total leucocyte count \\ TNF - Tumor necrosis factor \\ USG - Ultrasonogram \\ VEGF - Vascular endothelial growth factor \\ WBC - White blood cell \\ Yrs - Years
}

\section{BIBLIOGRAPHY}

1. Das S. Examination of acute abdomen, chapter 33, a Das $\mathrm{S}$, examination of acute abdomen, chapter 33 , a manual on clinical surgery, $8^{\text {th }}$ edition, Elsevier, page 435 to 456 .

2. Sharma MP, Bhatia V. Abdominal tuberculosis, Department of Gastroenterology. All India Institute of Medical Sciences, D II/23, Ansari Nagar, New Delhi 110029, India. mpsharma_s@hotmail.com, Indian J Med Res. 2004 Oct;120(4):305-15.

3. Oliak D, Yamini D, Udani VM, Lewis RJ, Vargas H, Arnell $\mathrm{T}$, et al. Can perforated appendicitis be diagnosed preoperatively based on admission factors? Department of Surgery, Harbor-UCLA Medical Center, Torrance, CA 90509, USA. J Gastrointest Surg. 2000 Sep-Oct;4(5):4704.

4. Grönroos JM, Grönroos P. Leukocyte count and Creactive protein in the diagnosis of acute appendicitis. Department of Surgery, University of Turku, Turku, Finland. Br J Surg 1999 Apr;86(4):501.

5. Grönroos JM. Clinical suspicion of acute appendicitis - is the time ripe for more conservative treatment? Departments of Surgery and Emergency, University of Turku, Turku, Finland. juha.gronroos@tyks.fi, Minim Invasive Ther Allied Technol. 2011 Jan;20(1):42-5. doi: 10.3109/13645706.2010.496958. Epub 2010 Jul 21.
6. Erdoğan D, Karaman I, Narci A, Karaman A, Cavuşoğlu YH, Aslan MK, et al. Comparison of two methods for the management of appendicular mass in children, Department of Pediatric Surgery, Dr. Sami Ulus Children's Hospital, 06080 Ankara, Turkey. deryaerdogan@hotmail.com, Pediatr Surg Int. 2005 Feb;21(2):81-3. Epub 2004 Dec 22.

7. Zarba Meli E, Mazzocchi P, Lepiane P, Dalsasso G, Giacovazzo F, Salvio A, et al. [The role of surgery in the treatment of appendicular abscesses]. II Clinical Chirurgica, Università degli Studi di Roma La Sapienza.

8. Hurme T, Nylamo E. Conservative versus operative treatment of appendicular abscess. Experience of 147 consecutive patients. Department of Paediatric Surgery, Turku University Central Hospital, Finland, Ann Chir Gynaecol. 1995;84(1):33-6. PMID:7645908.

9. Eriksson S, Styrud J. Interval appendicectomy: a retrospective study, Department of Surgery, Karolinska Institute at Danderyd Hospital, Sweden. Eur J Surg. 1998 Oct;164(10):771-4; discussion 775.

10. Lasson A, Lundagårds J, Lorén I, et al. Appendiceal abscesses: primary percutaneous drainage and selective interval appendicectomy, Department of Diagnostic Radiology, Malmö University Hospital, University of Lund, Sweden. Eur J Surg. 2002;168(5):264-9.

11. Hoffmann J, Lindhard A, Jensen HE. Appendix mass: conservative management without interval appendectomy. Am J Surg. 1984 Sep;148(3):379-82.

12. Corfield L. Interval appendicectomy after appendiceal mass or abscess in adults: what is "best practice?" Department of Surgery, University Hospital Lewisham, Lewisham High Street, London, SE13 6LH, UK, Surg Today. 2007;37(1):1-4. Epub 2007 Jan 1.

13. Sharp JF, Goldman M. Abdominal tuberculosis in East Birmingham--a 16 year study, Department of Surgery, East Birmingham Hospital, Bordesley Green East, UK, Postgrad Med J. 1987 Jul;63(741):539-14.

14. Balthazar EJ, Gordon R, Hulnick D. Ileocecal tuberculosis: CT and radiologic evaluation, Department of Radiology, New York University Medical Center, NY 10016. AJR Am J Roentgenol. 1990 Mar;154(3):499-503.

15. Uzunkoy A, Harma M, Harma M. Diagnosis of abdominal tuberculosis: experience from 11 cases and review of the literature, Department of Surgery, University of Harran, Faculty of Medicine, Sanliurfa, Turkey. World J Gastroenterol. 2004 Dec 15;10(24):3647-9.

16. Rai S, Thomas WM. Diagnosis of abdominal tuberculosis: the importance of laparoscopy. Department of General Surgery, Leicester General Hospital, Gwendolen Road, Leicester LE5 4PW, UK. sajal_rai@hotmail.com, J R Soc Med. 2003 Dec;96(12):586-8.

17. Immanuel C, Acharyulu GS, Kannapiran M, et al. Acute phase proteins in tuberculous patients. Tuberculosis Research Centre (Indian Council of Medical Research), Madras, Indian. J Chest Dis Allied Sci. 1990 JanMar;32(1):15-23.

18. Kosul'nikov SO, Kravchenko KV, Tarnopol'skiı̌ SA, et al. [The symptoms and surgical tactics for complicated forms of the abdominal cavity tuberculosis]. Klin Khir. 2012 Jan;(1):33-8.

19. Prakash A, Sharma LK, Koshal A, et al. Ileocaecal tuberculosis, Aust N Z J Surg. 1975 Nov;45(4):371-5. 
20. Muneef MA, Memish Z, Mahmoud SA, Sadoon SA, Bannatyne R, Khan Y. Tuberculosis in the belly: a review of forty-six cases involving the gastrointestinal tract and peritoneum, Dept. of Pediatrics, King Fahad National Guard Hospital, Riyadh, Saudi Arabia. Scand J Gastroenterol. 2001 May;36(5):528-32.

21. Stock C, Haug U, Brenner H. Population-based prevalence estimates of history of colonoscopy or sigmoidoscopy: review and analysis of recent trends. Division of Clinical Epidemiology and Aging Research, German Cancer Research Center, Heidelberg, Germany. Gastrointest Endosc. 2010 Feb;71(2):366-381.e2. doi: 10.1016/j.gie.2009.06.018. Epub 2009 Oct 20.

22. Mohandas KM, Desai DC. Epidemiology of digestive tract cancers in India. V. Large and small bowel, Division of Digestive Diseases and Nutrition, Tata Memorial Hospital, Mumbai. Indian J Gastroenterol. 1999 JulSep;18(3):118-21.

23. Li JN, Zhao L, Zheng WY, Miao Z, Tang XY, Qian JM. [The trends in clinical characteristics of colon cancer in last two decades], Peking Union Medical College Hospital, Peking Union Medical College, Chinese Academy of Medical Sciences, Beijing 100730, China. Zhonghua Nei Ke Za Zhi. 2010 Mar;49(3):226-9.

24. Sadahiro S, Suzuki T, Tokunaga N, Mukai M, Tajima $\mathrm{T}$, Makuuchi H, et al. Anemia in patients with colorectal cancer. Department of Surgery, Tokai University School of Medicine, Bohseidai, Isehara, Japan. J Gastroenterol. 1998 Aug;33(4):488-94.

25. Forslund A, Engarås B, Lönnroth $\mathrm{C}$, et al. Prediction of postoperative survival by preoperative serum concentrations of anti-p53 compared to CEA, CA 50, CA 242 and conventional blood tests in patients with colorectal carcinoma. Department of Surgery, Sahlgrenska University Hospital, Göteborg University, Sweden. Int J Oncol. 2002 May;20(5):1013-8.

26. Gür T, Demir H, Kotan MÇ. Tumor markers and biochemical parameters in colon cancer patients before and after chemotherapy. Division of Biochemistry, Health Sciences Faculty, Yuzuncu Yil University, Van, Turkey. gurtugba@hotmail.com, Asian Pac J Cancer Prev. 2011;12(11):3147-50.

27. Chung YC, Chang YF. Serum C-reactive protein correlates with survival in colorectal cancer patients, but is not an independent prognostic indicator. Department of Surgery, Hsin-Chu Hospital, No. 25, Lane 442, Sec. 1, Xhing-Kuo Road, Hsin-Chu City, Taiwan, Republic of China. young@hch.gov.tw, Eur J Gastroenterol Hepatol. 2003 Apr;15(4):369-73.

28. Strøm E, Larsen JL. Colon cancer at barium enema examination and colonoscopy: a study from the county of Hordaland, Norway. Department of Radiology, University Hospital of Bergen, Haukeland Hospital, Norway, Radiology. 1999 Apr;211(1):211-4.
29. Herfarth C, Runkel N. [Surgical standards in primary colon cancer], Chirurgische Klinik, Universität Heidelberg.

30. Aïssa A, Alouini-Mekki R, Ben Abdallah A, Enaifar $\mathrm{R}$, Kobbi I, Stita W, et al. [Update on the management of desmoids tumors], Service d'imagerie médicale, hôpital Ibn EL Jazzar, 3100 Kairouan, Tunisie. aissa_amene@yahoo.fr, Gynecol Obstet Fertil. 2012 Feb;40(2):104-8. doi: 10.1016/j.gyobfe.2011.07.055. Epub 2012 Jan 16.

31. Vilar FC, Neves FF, Colares JK, et al. [Spinal tuberculosis (Pott's disease) associated to psoas abscess: report of two cases and a literature review], Divisão de Moléstias Infecciosas, Departamento de Clínica Médica, Faculdade de Medicina de Ribeirão Preto, Universidade de São Paulo, Av. Bandeirantes 3900, 14048-900 Ribeirão Preto, SP. Rev Soc Bras Med Trop. 2006 May-Jun;39(3):278-82.

32. Rajagopal AS, Shinkfield M, Voight $S$, et al. Massive rectus sheath hematoma. Department of Surgery, St Mary's Hospital, Newport, Isle of Wight, P030 5TG, United Kingdom. ambil@mailcity.com, Am J Surg. 2006 Jan;191(1):126-7.

33. Rai BR, Chaudhary D, Thapa P, Joshi MR, Dangol UM, Singh DR. Ancient cystic pelvic schwannoma presenting as a right iliac fossa mass, Department of Surgery, Kathmandu Medical College Teaching Hospital, Sinamangal, Nepal. bhabirai@hotmail.com. Kathmandu Univ Med J (KUMJ). 2005 Jul-Sep;3(3):285-8.

34. Millard FC, Collins MC, Peck RJ. Ultrasound in the investigation of the right iliac fossa mass. Department of Radiology, Royal Hallamshire Hospital, Sheffield, Br J Radiol. 1991 Jan;64(757):17-9.

35. Jain R, Sawhney S, Bhargava DK, et al. Diagnosis of abdominal tuberculosis: sonographic findings in patients with early disease. Department of Radiodiagnosis. All India Institute of Medical Sciences, New Delhi, India. AJR Am J Roentgenol. 1995 Dec;165(6):1391-5.

36. Martínez-Ares D, Martín-Granizo Barrenechea I, SoutoRuzo J, Yáñez López J, Pallarés Peral A, Vázquez-Iglesias JL. The value of abdominal ultrasound in the diagnosis of colon cancer, Service of Digestive Diseases. Complejo Hospitalario Universitario XeralCíes, Vigo, Pontevedra, Spain. dmartinezares@sepd.es,Rev Esp Enferm Dig. 2005 Dec;97(12):877-86. 